in vivo $34: 3687-3703(2020)$

doi:10.21873/invivo.12217

\title{
Gender-specific Performance of a Diagnostic Score in Acute Appendicitis
}

\author{
JANNICA MEKLIN $^{1 *}$, MAARET ESKELINEN $^{1 *}$, KARI SYRJÄNEN $^{2,3}$ and MATTI ESKELINEN ${ }^{1}$ \\ ${ }^{1}$ Department of Surgery, Kuopio University Hospital and School of Medicine, \\ University of Eastern Finland, Kuopio, Finland; \\ ${ }^{2}$ Molecular Oncology Research Center, Barretos Cancer Hospital, Barretos, Brazil; \\ ${ }^{3}$ SMW Consultants, Ltd., Kaarina, Finland
}

\begin{abstract}
Background/Aim: Although a negative appendectomy in female patients with acute abdominal pain (AAP) can be twice as frequent as in male patients, the accuracy of diagnostic scores (DSs) in acute appendicitis (AA) is rarely considered among patients with $A A P$. The aim was to study the gender-specific performance of a DS in AA. Patients and Methods: As an extension of the World Organisation of Gastro-Enterology Research Committee (OMGE) AAP study, 1,333 patients presenting with AAP were included in the study. The clinical history and diagnostic symptoms $(n=22)$, signs $(n=14)$ and laboratory tests $(n=3)$ were recorded in each patient. Results: The most significant diagnostic predictors were used to construct DS formulas for AA diagnosis, separately for both genders. The formulas were tested at 6 different cutoff levels to find the best diagnostic performance for $A A$ in females and males. The highest specificities of the $D S_{L C-}[D S$ without leucocyte count (LC)] and $D S_{L C+}(D S$ with $L C)$ scores in detecting $A A$ were $98 \%$ (95\% CI=97-99\%) and 98\% (95\% $C I=96-99 \%)$, respectively. In the ROC comparison test, there was no statistically significant difference in the performance of $D S_{L C-}$ and $D S_{L C+}$ in female and male patients. Conclusion: Our gender-specific DS reached very high AUC values for $A A$ (0.948-0.956) in both genders, and there was no statistically significant difference in the AUC values of $D S_{L C-}$ and $D S_{L C+}$ between women and men with AAP.
\end{abstract}

This article is freely accessible online.

*These Authors contributed equally to this study.

Correspondence to: Matti Eskelinen, MD, Ph.D., School of Medicine, University of Eastern Finland, P.O. Box 100, FI-70029 KYS, Finland. Tel: +358 17173311, Fax: +358 17172611, GSM: +358 400969444, e-mail: matti.eskelinen@kuh.fi

Key Words: Acute appendicitis, acute abdominal pain, diagnostic score, female, male, leucocyte count, ROC, HSROC, diagnostic accuracy.
Acute appendicitis (AA) with appendectomy is the most common cause of acute surgical abdomen in the Western countries (1). In a recent meta-analysis, Ferris et al. (1) showed that the pooled incidence of the AA with appendectomy was $100 / 100,000$ person years (py) $(95 \% \mathrm{CI}=91-100 \%)$ in the 2000's in Northern America, and they estimated that the number of AA cases in 2015 was 378,614. In Europe, the pooled incidence ranged from $151 / 100,000$ py in Western Europe to $105 / 100,000$ py in Eastern Europe. The incidence of AA has remained quite stable in most Western countries but in the newly industrialized countries AA is rapidly rising, with the pooled incidence of AA in South Korea being 206/100,000 py, Turkey $160 / 100,000$ py and Chile 202/100,000 py.

We recently designed a diagnostic score (DS) to improve the diagnostic precision in distinguishing AA from non-specific abdominal pain (NSAP) (2). Our experience suggests that DS could assist the clinician in differentiating AA from NSAP and other causes of acute abdominal pain (AAP), although leucocyte count (LC) does not improve the diagnostic performance of a DS in AA (2). Given that the incidence of AA is higher in female patients presenting with AAP than in male patients (3) and to get more insight into the important symptoms, signs and tests related to the clinical diagnosis of AA, we assessed the performance of the DS model i) without leucocyte count $\left(\mathrm{DS}_{\mathrm{LC}_{-}}\right)$and ii) with leucocyte count $\left(\mathrm{DS}_{\mathrm{LC}+}\right)$, separately in female and male patients with AA.

\section{Patients and Methods}

Criteria for inclusion in this study and the diagnostic criteria were those set out by the Research Committee of the World Organization of Gastroenterology (OMGE) $(2,4,5,6,7,8)$. There were 636 men $(47.7 \%)$ and 697 women $(52.3 \%)$ with mean age $( \pm$ SD) of $38.0 \pm 22.1$ years $(2)$.

The examination of the clinical symptoms, signs and tests were conducted using a standard technique and the results were graded positive or negative as previously described (2) (Tables I and II). The diagnosis of AA was done by considering all symptoms, signs and results of the laboratory tests together and the diagnostic criteria of AA $(2,4-7)$. 
Table I. The clinical history of the patients with acute appendicitis versus other diagnosis of acute abdominal pain.

\begin{tabular}{|c|c|c|c|c|c|c|c|c|c|c|}
\hline \multirow[t]{2}{*}{ Clinical history variable } & \multirow[t]{2}{*}{$\begin{array}{l}\text { Positive } \\
\text { endpoint }\end{array}$} & \multirow[t]{2}{*}{$\begin{array}{l}\text { Negative } \\
\text { endpoint }\end{array}$} & \multicolumn{2}{|c|}{$\begin{array}{c}\text { TP } \\
\text { Gender }\end{array}$} & \multicolumn{2}{|c|}{$\begin{array}{l}\text { FN } \\
\text { Gender }\end{array}$} & \multicolumn{2}{|c|}{$\begin{array}{c}\text { FP } \\
\text { Gender }\end{array}$} & \multicolumn{2}{|c|}{$\begin{array}{c}\text { TN } \\
\text { Gender }\end{array}$} \\
\hline & & & $\mathrm{F}$ & M & $\mathrm{F}$ & M & $\mathrm{F}$ & M & $\mathrm{F}$ & M \\
\hline $\begin{array}{l}\text { 1. Location of initial } \\
\text { pain }\end{array}$ & $\begin{array}{l}\text { Upper quadrant } \\
\text { of abdomen }\end{array}$ & $\begin{array}{l}\text { Other quadrants } \\
\text { of abdomen }\end{array}$ & 4 & 2 & 117 & 147 & 94 & 52 & 482 & 435 \\
\hline $\begin{array}{l}\text { 2. Location of pain } \\
\text { at diagnosis }\end{array}$ & $\begin{array}{l}\text { Right lower quadrant } \\
\text { of abdomen }\end{array}$ & $\begin{array}{l}\text { Other quadrants } \\
\text { of abdomen }\end{array}$ & 94 & 113 & 27 & 36 & 156 & 93 & 420 & 394 \\
\hline $\begin{array}{l}\text { 3. Intensity of } \\
\text { abdominal pain }\end{array}$ & $\begin{array}{l}\text { Subjectively moderate/ } \\
\text { intolerable pain }\end{array}$ & Weak pain & 77 & 102 & 44 & 47 & 381 & 313 & 195 & 174 \\
\hline $\begin{array}{l}\text { 4. Progression of pain } \\
\text { from onset to } \\
\text { diagnosis }\end{array}$ & $\begin{array}{l}\text { Subjectively same } \\
\text { or worse pain }\end{array}$ & $\begin{array}{l}\text { Weaker pain than } \\
\text { at the onset }\end{array}$ & 86 & 112 & 35 & 37 & 388 & 302 & 188 & 185 \\
\hline 5. Type of pain & Subjectively steady pain & $\begin{array}{c}\text { Colicky or intermittent } \\
\text { pain }\end{array}$ & 109 & 81 & 40 & 40 & 256 & 285 & 231 & 291 \\
\hline 6. Aggravating factors & $\begin{array}{l}\text { Movement, coughing, } \\
\text { respiration, food or other }\end{array}$ & No aggravating factors & 112 & 132 & 9 & 17 & 409 & 324 & 167 & 163 \\
\hline 7. Relieving factors & No relieving factors & $\begin{array}{l}\text { Vomiting, lying still, } \\
\text { food, antacids or no } \\
\text { relieving factors }\end{array}$ & 24 & 28 & 97 & 121 & 192 & 190 & 384 & 297 \\
\hline 8. Previous similar pain & No & Yes & 103 & 126 & 16 & 19 & 335 & 308 & 236 & 176 \\
\hline 9. Vertigo & No & Yes & 121 & 149 & 0 & 0 & 547 & 472 & 28 & 12 \\
\hline 10. Nausea & Yes & No & 74 & 80 & 47 & 69 & 345 & 272 & 231 & 215 \\
\hline 11. Vomiting & Yes & No & 58 & 71 & 63 & 78 & 230 & 216 & 346 & 271 \\
\hline 12. Appetite & No appetite & Normal appetite & 100 & 119 & 21 & 30 & 421 & 337 & 155 & 150 \\
\hline 13. Previous indigestion & No & Yes & 111 & 129 & 10 & 20 & 444 & 368 & 131 & 118 \\
\hline 14. Jaundice & No & Yes & 121 & 148 & 0 & 1 & 557 & 476 & 19 & 11 \\
\hline 15. Bowels & Normal & $\begin{array}{l}\text { Constipation, diarrhea, } \\
\text { blood, mucus, white } \\
\text { or normal stools }\end{array}$ & 102 & 124 & 19 & 25 & 434 & 355 & 142 & 132 \\
\hline 16. Micturition & Normal & Abnormal & 115 & 148 & 6 & 1 & 535 & 449 & 41 & 38 \\
\hline $\begin{array}{l}\text { 17. Drugs for abdominal } \\
\text { pain }\end{array}$ & No & Yes & 120 & 148 & 1 & 1 & 552 & 458 & 24 & 28 \\
\hline $\begin{array}{l}\text { 18. Previous abdominal } \\
\text { surgery }\end{array}$ & No & Yes & 101 & 146 & 20 & 3 & 584 & 368 & 192 & 118 \\
\hline $\begin{array}{l}\text { 19. Previous abdominal } \\
\text { diseases }\end{array}$ & No & Yes & 111 & 138 & 10 & 11 & 463 & 387 & 113 & 99 \\
\hline 20. Use of alcohol & No & Yes & 121 & 149 & 0 & 0 & 567 & 463 & 9 & 23 \\
\hline
\end{tabular}

TP, true positive; FN, false negative; FP, false positive; TN, true negative.

Identifying the DS models. In the computation of the diagnostic score (DS), a multivariate logistic (stepwise) regression analysis (SPSS Statistics 26.0.0.1; IBM, NY, USA) was used to disclose the variables with an independent predictive value. All the variables presented in Tables I and II were included in the analysis as binary data e.g. $\mathrm{AA}=1$ and other diagnosis of $\mathrm{AAP}=0$. Using the coefficients of the regression model, a DS was built and its predictive value for AA was studied. The coefficient of the multivariate analysis shows the relative risk $\left(\mathrm{RR}=\mathrm{e}_{-}, \mathrm{n}=\boldsymbol{\beta}\right)$ of a patient with a given symptom or sign to have an AA.

The formula without $L C\left(D S_{L C-}\right)$ in women. The formula without $\mathrm{LC}$, showing the highest diagnostic performance for AA in HSROC analysis is as follows $\mathrm{DS}_{\mathrm{LC}}=2.98 \times$ tenderness (positive endpoint $=1$, negative endpoint $=0)+2.45 \times$ rigidity (positive endpoint $=1$, negative endpoint $=0$ ) $+2.08 \times$ guarding (positive endpoint=1, negative endpoint $=0$ ) $+1.33 \times$ pain at diagnosis (positive endpoint $=1$, negative endpoint $=0$ ) $+0.88 \times$ renal tenderness (positive endpoint $=1$, negative endpoint $=0)-7.22$. The mean $(\mathrm{SD})$ of $\mathrm{DS}_{\mathrm{LC}-}$ values for $\mathrm{AA}$ in women $(n=121)$ were $0.61(1.81)$ and the $\mathrm{DS}_{\mathrm{LC}-}$ mean $(\mathrm{SD})$ values for all female patients with AAP ( $\mathrm{n}=697)$ were -3.41 (2.84) (Table III).

The formula with $L C\left(D S_{L C+}\right)$ in women. The formula with LC, showing the highest diagnostic performance for AA in women is as follows $\mathrm{DS}_{\mathrm{LC}+}=3.17 \times$ tenderness (positive endpoint=1, negative endpoint $=0$ ) $+2.39 \times$ rigidity (positive endpoint $=1$, negative endpoint $=0$ ) $+2.00 \times$ guarding (positive endpoint $=1$, negative endpoint $=0)+1.63 \times \mathrm{LC}+1.45 \times$ pain at diagnosis (positive endpoint $=1$, negative endpoint $=0$ ) $+0.77 \times$ renal tenderness (positive endpoint $=1$, negative endpoint $=0)-7.80$. The mean $(\mathrm{SD})$ of $\mathrm{DS}_{\mathrm{LC}}$ - values for $\mathrm{AA}$ in women $(\mathrm{n}=111)$ were $1.32(1.81)$ and $\mathrm{DS}_{\mathrm{LC}+}$ mean $(\mathrm{SD})$ values for all women with AAP $(\mathrm{n}=575)$ were -3.10 (3.21) (Table IV). 
Meklin et al: Gender-specific Performance of a Diagnostic Score in Acute Appendicitis

Table II. The clinical signs and tests of patients with acute appendicitis versus other diagnosis of acute abdominal pain.

\begin{tabular}{|c|c|c|c|c|c|c|c|c|c|c|}
\hline \multirow[t]{2}{*}{$\begin{array}{l}\text { Clinical history variable } \\
\text { and investigations }\end{array}$} & \multirow[t]{2}{*}{$\begin{array}{l}\text { Positive } \\
\text { endpoint }\end{array}$} & \multirow[t]{2}{*}{$\begin{array}{l}\text { Negative } \\
\text { endpoint }\end{array}$} & \multicolumn{2}{|c|}{$\begin{array}{c}\text { TP } \\
\text { Gender }\end{array}$} & \multicolumn{2}{|c|}{$\begin{array}{c}\text { FN } \\
\text { Gender }\end{array}$} & \multicolumn{2}{|c|}{$\begin{array}{l}\text { FP } \\
\text { Gender }\end{array}$} & \multicolumn{2}{|c|}{$\begin{array}{l}\text { TN } \\
\text { Gender }\end{array}$} \\
\hline & & & $\mathrm{F}$ & M & $\mathrm{F}$ & M & $\mathrm{F}$ & M & $\mathrm{F}$ & M \\
\hline 1. Mood & Normal & Distressed or anxious & 103 & 130 & 18 & 19 & 482 & 391 & 94 & 96 \\
\hline 2. Colour & Normal & $\begin{array}{l}\text { Jaundiced, flushed, } \\
\text { pale or cyanosed }\end{array}$ & 112 & 133 & 9 & 16 & 506 & 430 & 70 & 57 \\
\hline 3. Abdominal movement & Normal & Poor/nil & 109 & 136 & 12 & 13 & 543 & 451 & 33 & 35 \\
\hline 4. Scar & No & Yes & 101 & 145 & 20 & 4 & 375 & 365 & 201 & 121 \\
\hline 5. Distension & No & Yes & 118 & 146 & 3 & 3 & 532 & 440 & 42 & 45 \\
\hline 6. Tenderness & $\begin{array}{l}\text { Right lower quadrant } \\
\text { of abdomen }\end{array}$ & $\begin{array}{l}\text { Other quadrants } \\
\text { of abdomen }\end{array}$ & 113 & 135 & 8 & 14 & 170 & 110 & 406 & 377 \\
\hline 7. Mass & No & Yes & 120 & 149 & 1 & 0 & 551 & 479 & 25 & 8 \\
\hline 8. Rebound & Yes & No & 111 & 136 & 10 & 13 & 221 & 163 & 355 & 324 \\
\hline 9. Guarding & Yes & No & 110 & 133 & 11 & 16 & 237 & 227 & 339 & 260 \\
\hline 10. Rigidity & Yes & No & 73 & 98 & 48 & 51 & 57 & 66 & 519 & 420 \\
\hline 11. Murphy's positive & No & Yes & 117 & 142 & 4 & 7 & 499 & 450 & 77 & 36 \\
\hline 12. Bowel sounds & Normal & Abnormal & 106 & 130 & 15 & 19 & 510 & 398 & 66 & 89 \\
\hline 13. Renal tenderness & No & Yes & 90 & 110 & 31 & 39 & 410 & 362 & 166 & 125 \\
\hline 14. Rectal digital tenderness & Abnormal & Normal & 70 & 72 & 51 & 77 & 152 & 70 & 424 & 417 \\
\hline 15. Body temperature (Temp) & $>37.1^{\circ} \mathrm{C}$ & $\leq 37.1^{\circ} \mathrm{C}$ & 71 & 104 & 48 & 42 & 201 & 150 & 329 & 287 \\
\hline 16. Leucocyte count (LC) & $>10,000 / \mathrm{mm}^{3}$ & $\leq 10,000 / \mathrm{mm}^{3}$ & 73 & 117 & 38 & 19 & 129 & 146 & 335 & 224 \\
\hline 17. Urine & Normal & Haematuria or bacteriuria & 105 & 136 & 1 & 0 & 481 & 374 & 32 & 39 \\
\hline
\end{tabular}

TP, True positive; FN, false negative; FP, false positive; TN, true negative.

The formula without $L C\left(D S_{L C-}\right)$ in men. The formula without $\mathrm{LC}$, showing the highest diagnostic performance for AA in HSROC analysis is as follows $\mathrm{DS}_{\mathrm{LC}}=1.97 \times$ tenderness (positive endpoint $=1$, negative endpoint $=0)+1.88 \times$ previous abdominal surgery (positive endpoint $=1$, negative endpoint $=0$ ) $+1.61 \times$ rebound (positive endpoint $=1$, negative endpoint $=0$ ) $+1.43 \times$ rigidity (positive endpoint $=1$, negative endpoint $=0)+1.30 \times$ pain at diagnosis (positive endpoint $=1$, negative endpoint $=0$ ) $+1.14 \times$ guarding (positive endpoint $=1$, negative endpoint $=0$ ) $+1.05 \times$ body temperature (positive endpoint $=1$, negative endpoint=0)-7.69. The mean (SD) $\mathrm{DS}_{\mathrm{LC}-}$ values for $\mathrm{AA}$ in males $(\mathrm{n}=149)$ were $-1.13(1.74)$ and $\mathrm{DS}_{\mathrm{LC}-}$ mean $(\mathrm{SD})$ values for all men with AAP $(n=636)$ were -2.63 (3.05) (Table V).

The formula with $L C\left(D S_{L C+}\right)$ in men. The formula with $\mathrm{LC}$, showing the highest diagnostic performance for AA in men is as follows $\mathrm{DS}_{\mathrm{LC}+}=2.51 \times$ previous abdominal surgery (positive endpoint $=1$, negative endpoint $=0)+2.18 \times \mathrm{LC}$ (positive endpoint $=1$, negative endpoint $=0)+1.58 \times$ pain at diagnosis (positive endpoint $=1$, negative endpoint $=0$ ) $\times 1.41 \times$ tenderness (positive endpoint $=1$, negative endpoint $=0)+1.25 \times$ rigidity $($ positive endpoint $=1$, negative endpoint $=0$ ) $+1.04 \times$ rebound (positive endpoint=1, negative endpoint $=0)+0.97 \times$ guarding $+0.81 \times$ rectal digital tenderness $+0.74 \times$ body temperature-8.86. The mean (SD) $\mathrm{DS}_{\mathrm{LC}-}$ values for $\mathrm{AA}$ in males $(\mathrm{n}=133)$ were $1.58(1.77)$ and $\mathrm{DS}_{\mathrm{LC}+}$ mean $(\mathrm{SD})$ values for all male patients with AAP $(\mathrm{n}=476)$ were -2.33 (2.21) (Table VI).

Statistical analysis. The other statistical analyses were performed using STATA/SE version 16.1 (StataCorp, College Station, TX, USA). Statistical tests presented were two-sided, and $P$-value $<0.05$ was considered statistically significant. Using $2 \times 2$ tables, we calculated sensitivity (Se) and specificity (Sp) with $95 \%$ confidence intervals
(95\% CI) for each symptom, sign or test, and created separate forest plots for showing each set of data, separately for each diagnostic variable. We calculated the summary estimates of sensitivity (Se) and specificity (Sp), positive (LR+) and negative likelihood ratio (LR-) and diagnostic odds ratio (DOR), using a random effect bivariate model and fitted the summary hierarchical receiving operating characteristic (HSROC) curves, including all diagnostic variables in the $\mathrm{DS}_{\mathrm{LC}-}$ and $\mathrm{DS}_{\mathrm{LC}+}$ models, using the AA endpoint.

Using the STATA's predict tool, we also made posterior predictions [Empirical Bayes (EB) estimates] of the Se and Sp in each variables in both female and male AA patients in $\mathrm{DS}_{\mathrm{LC}-}$ and $\mathrm{DS}_{\mathrm{LC}+}$ Analogous to its use in meta-analysis, EB estimates here give the best estimates of the true $\mathrm{Se}$ and $\mathrm{Sp}$ for each diagnostic variable, the variable-specific point estimates usually shrinking toward the summary point of the HSROC. We explored the statistical heterogeneity between diagnostic variables and DS models through visual examination of the forest plots and the HSROC curves. To study the potential bias, we used the Cook's distance to check for the particularly influential variables, together with a scatter plot of the standardised (level 2) residuals to find out the variables that are distinct outliers.

\section{Results}

Diagnostic performance of the symptoms. The pooled overall gender-specific (F vs. M) Se of the diagnostic symptoms for detecting AA was $80 \%(95 \% \mathrm{CI}=67 \%-90 \%)$ and $81 \%(95 \%$ $\mathrm{CI}=82-94 \%$ ), respectively (Figures 1 and 2). In women Se was higher than $80 \%$ for 12 diagnostic symptoms, while in men Se was higher than $81 \%$ for 11 diagnostic symptoms. 
Table III. Diagnostic score of female patients $(n=697)$ without leucocyte count $\left(D S_{L C-}\right)$ shown at six different cut-off levels of symptoms, signs and test.

\begin{tabular}{|c|c|c|c|c|c|c|}
\hline Diagnostic score (DS) & Positive endpoint & Negative endpoint & $\mathrm{TP}$ & FN & FP & $\mathrm{TN}$ \\
\hline 1. Logistic model without leucocyte count $\mathrm{DS}_{\mathrm{LC}-} \mathrm{I}$ & Appendicitis & Other diagnosis of acute abdominal pain & 114 & 7 & 147 & 429 \\
\hline 2. Logistic model without leucocyte count $\mathrm{DS}_{\mathrm{LC}-}$ II & Appendicitis & Other diagnosis of acute abdominal pain & 108 & 13 & 69 & 507 \\
\hline 3. Logistic model without leucocyte count $\mathrm{DS}_{\mathrm{LC}}$ III & Appendicitis & Other diagnosis of acute abdominal pain & 103 & 18 & 50 & 526 \\
\hline 4. Logistic model without leucocyte count $\mathrm{DS}_{\mathrm{LC}-}$ IV & Appendicitis & Other diagnosis of acute abdominal pain & 99 & 22 & 39 & 537 \\
\hline 5. Logistic model without leucocyte count $\mathrm{DS}_{\mathrm{LC}-} \mathrm{V}$ & Appendicitis & Other diagnosis of acute abdominal pain & 97 & 24 & 36 & 540 \\
\hline 6. Logistic model without leucocyte count $\mathrm{DS}_{\mathrm{LC}-} \mathrm{VI}$ & Appendicitis & Other diagnosis of acute abdominal pain & 99 & 7 & 39 & 429 \\
\hline
\end{tabular}

TP, True positive; FN, false negative; FP, false positive; TN, true negative. Cut-off levels: DS I=-2.03, DS II=-1.4, DS III=-0.90, DS IV=-0.49, DS V=0.03, VI=-2.03- -0.49 (follow-up patients $n=123$ ).

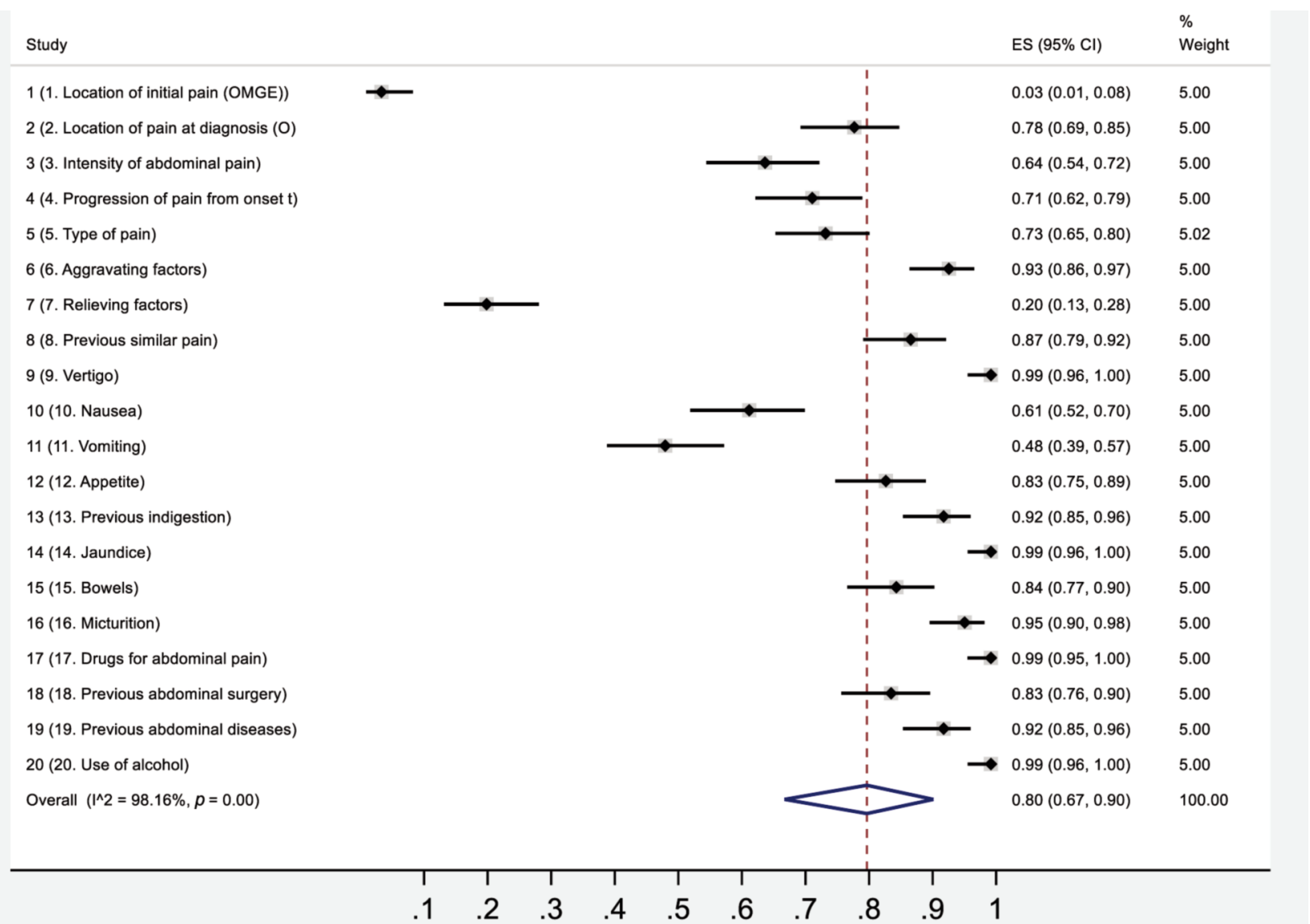

Figure 1. Pooled sensitivities of the clinical symptoms in acute appendicitis (random-effects model) in women. ES: Estimated sensitivity; CI: Confidence interval.

The five best diagnostic symptoms in women (vertigo, jaundice, micturition, drugs for abdominal pain and use of alcohol) showed 95-99\% Se, whereas in men (vertigo, jaundice, micturition, drugs for abdominal pain and use of alcohol) showed 99-100\% Se in diagnosis of AA (Figure 2). The pooled overall $\mathrm{Sp}$ of the diagnostic symptoms for detecting AA was 30\% (95\% CI=19\%-42\%) and 31\% (95\%
$\mathrm{CI}=20-43 \%$ ) for women and men, respectively (Figures 3 and 4). In women 9 diagnostic symptoms showed Sp higher than $30 \%$, while in men Sp exceeded $31 \%$ for 10 diagnostic symptoms. The five best diagnostic symptoms in diagnosis of AA among women (location of initial pain, location of pain at diagnosis, type of pain, relieving factors, vomiting) showed $60-84 \%$ Sp while those (location of initial pain, 
Table IV. Diagnostic score of female patients $(n=575)$ with leucocyte count $\left(D S_{L C+}\right)$ shown as six different cut-off levels of symptoms, signs and test.

\begin{tabular}{|c|c|c|c|c|c|c|}
\hline Diagnostic score (DS) & Positive endpoint & Negative endpoint & ТP & FN & FP & $\mathrm{TN}$ \\
\hline 1. Logistic model with leucocyte count $\mathrm{DS}_{\mathrm{LC}+}$ VII & Appendicitis & Other diagnosis of acute abdominal pain & 107 & 4 & 192 & 272 \\
\hline 2.Logistic model with leucocyte count $\mathrm{DS}_{\mathrm{LC}+}$ VIII & Appendicitis & Other diagnosis of acute abdominal pain & 104 & 7 & 105 & 359 \\
\hline 3. Logistic model with leucocyte count $\mathrm{DS}_{\mathrm{LC}+}$ IX & Appendicitis & Other diagnosis of acute abdominal pain & 101 & 10 & 62 & 402 \\
\hline 4. Logistic model with leucocyte count $\mathrm{DS}_{\mathrm{LC}+} \mathrm{X}$ & Appendicitis & Other diagnosis of acute abdominal pain & 97 & 14 & 35 & 429 \\
\hline 5. Logistic model with leucocyte count $\mathrm{DS}_{\mathrm{LC}+} \mathrm{XI}$ & Appendicitis & Other diagnosis of acute abdominal pain & 85 & 26 & 20 & 444 \\
\hline 6. Logistic model with leucocyte count $\mathrm{DS}_{\mathrm{LC}+}$ XII & Appendicitis & Other diagnosis of acute abdominal pain & 97 & 7 & 35 & 359 \\
\hline
\end{tabular}

TP, True positive; FN, false negative; FP, false positive; TN, true negative. Cut-off levels: DS I=-3.2, DS II=-2.33, DS III=-0.80, DS IV=-0.41, DS V=0.10, VI=-2.33- -0.41 (follow-up patients $n=77$ ).

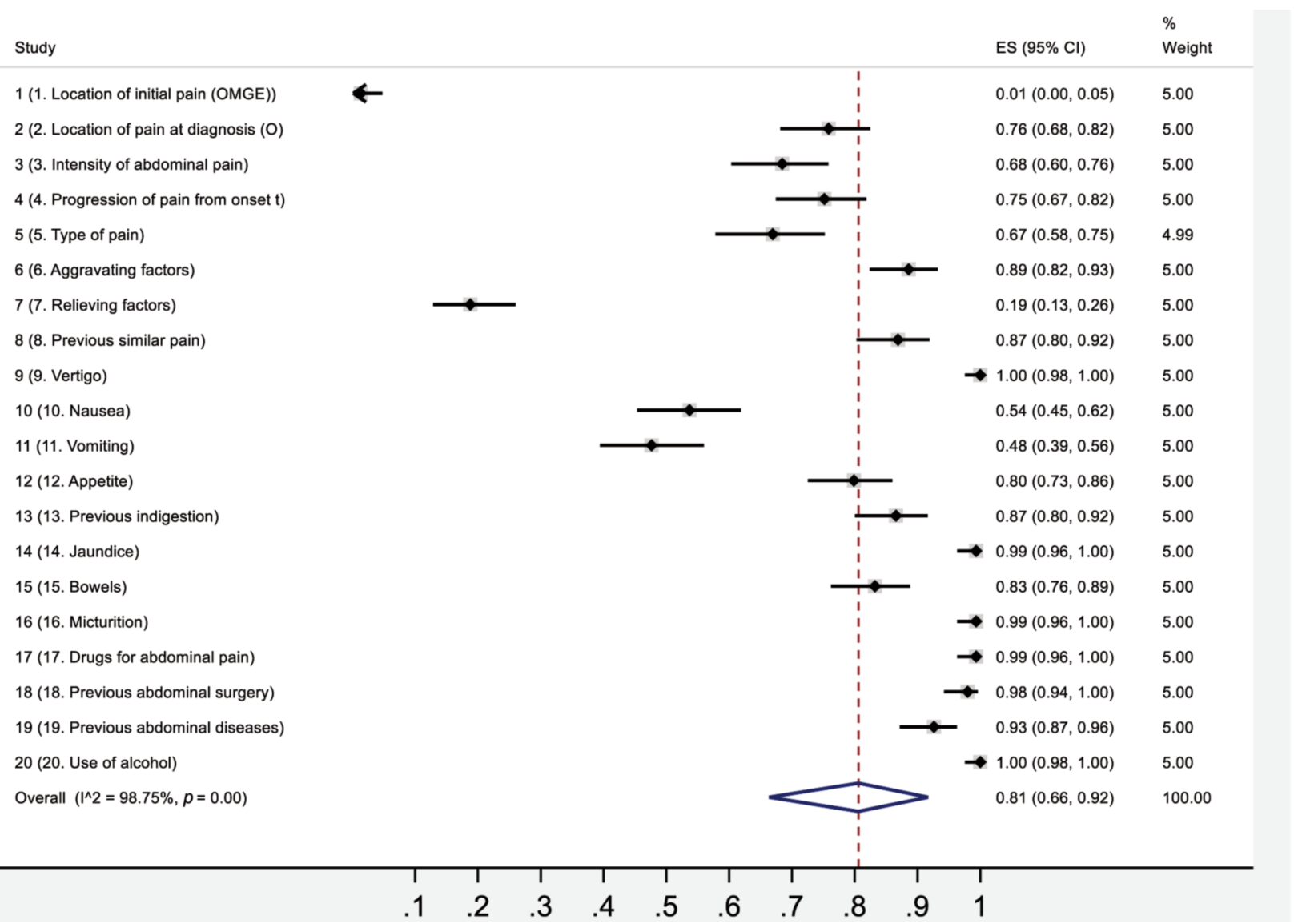

Figure 2. Pooled sensitivities of the clinical symptoms in acute appendicitis (random-effects model) in men. ES: Estimated specificity; CI: Confidence interval.

location of pain at diagnosis, type of pain, relieving factors, vomiting) in men showed Sp of 51-89\% (Figure 4).

Diagnostic performance of the signs and tests. The pooled overall Se of the diagnostic signs and tests for detecting AA was $86 \%(95 \% \mathrm{CI}=79 \%-92 \%)$ and $88 \%(95 \% \mathrm{CI}=82-94 \%)$, for women and men, respectively (Figures 5 and 6). In women 10 diagnostic signs and tests had Se exceeding $86 \%$, while in men Se was higher than $88 \%$ for 10 diagnostic signs and tests. In diagnosis of AA the five best diagnostic signs and tests in women (distension, tenderness, mass, Murphy's sign, urine) showed 93-99\% Se whereas those (scar, distension, mass, Murphy's sign, urine) in men showed 9599\% Se (Figure 6). The pooled overall Sp of the signs and 
Table V. Diagnostic score of male patients $(n=636)$ without leucocyte count $\left(D S_{L C-}\right)$ shown as six different cut-off levels of symptoms, signs and test.

\begin{tabular}{|c|c|c|c|c|c|c|}
\hline Diagnostic score (DS) & Positive endpoint & Negative endpoint & $\mathrm{TP}$ & FN & FP & $\mathrm{TN}$ \\
\hline 1. Logistic model without leucocyte count $\mathrm{DS}_{\mathrm{LC}-} \mathrm{I}$ & Appendicitis & Other diagnosis of acute abdominal pain & 142 & 4 & 174 & 261 \\
\hline 2. Logistic model without leucocyte count $\mathrm{DS}_{\mathrm{LC}-}$ II & Appendicitis & Other diagnosis of acute abdominal pain & 140 & 6 & 144 & 291 \\
\hline 3. Logistic model without leucocyte count $\mathrm{DS}_{\mathrm{LC}}$ III & Appendicitis & Other diagnosis of acute abdominal pain & 139 & 7 & 101 & 334 \\
\hline 4. Logistic model without leucocyte count $\mathrm{DS}_{\mathrm{LC}-}$ IV & Appendicitis & Other diagnosis of acute abdominal pain & 131 & 15 & 66 & 369 \\
\hline 5. Logistic model without leucocyte count $\mathrm{DS}_{\mathrm{LC}-} \mathrm{V}$ & Appendicitis & Other diagnosis of acute abdominal pain & 125 & 21 & 40 & 395 \\
\hline 6. Logistic model without leucocyte count $\mathrm{DS}_{\mathrm{LC}-} \mathrm{VI}$ & Appendicitis & Other diagnosis of acute abdominal pain & 125 & 7 & 40 & 334 \\
\hline
\end{tabular}

TP, True positive; FN, false negative; FP, false positive; TN, true negative. Cut-off levels: DS I=-3.1, DS II=-2.6, DS III=-2.0, DS IV=-1,4, DS $\mathrm{V}=-0.48$, VI $=-2.00-0.48$ (follow-up patients $\mathrm{n}=75$ ).

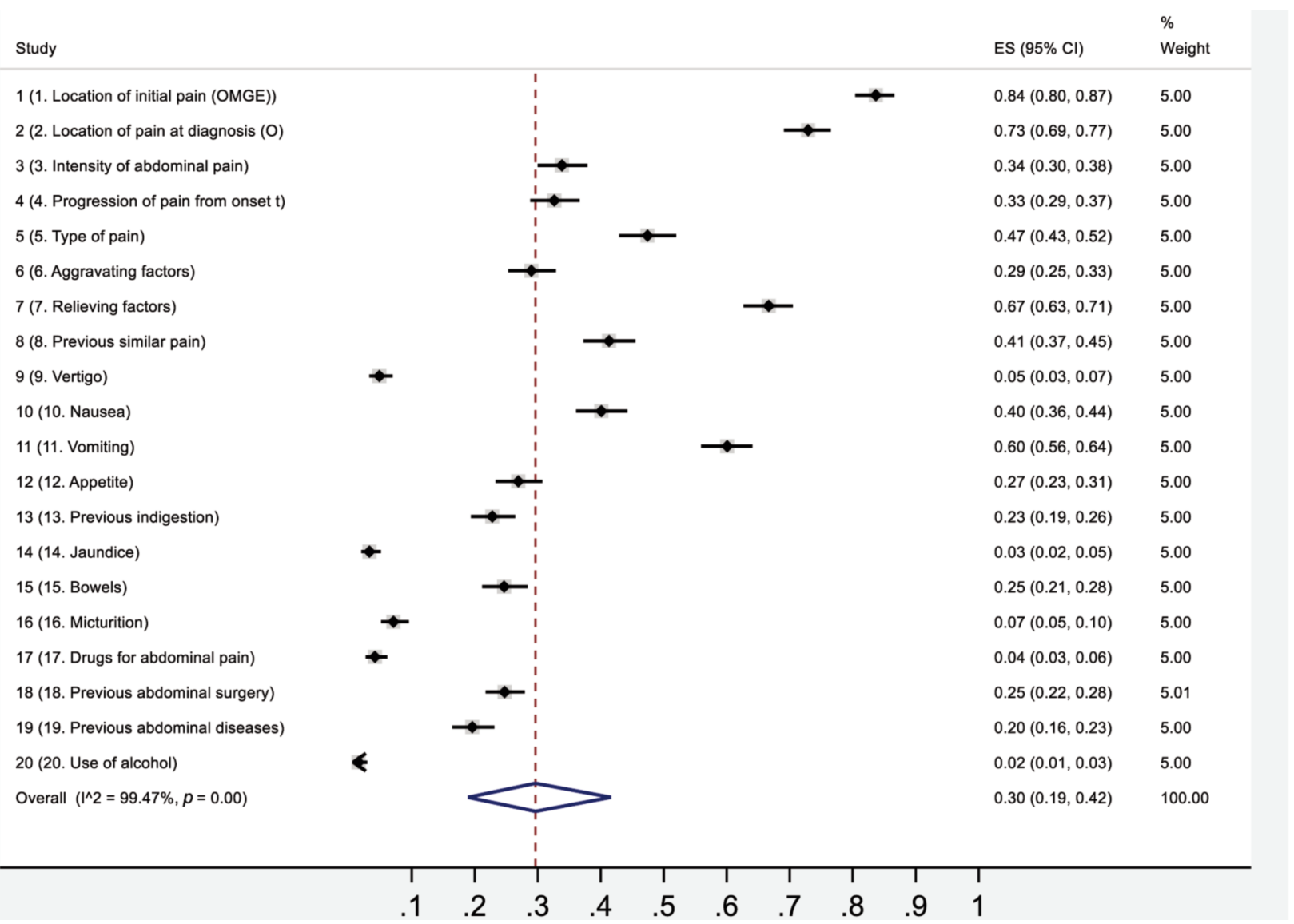

Figure 3. Pooled specificities of the clinical symptoms in acute appendicitis (random-effects model) in women. ES: Estimated specificity; CI: Confidence interval.

tests was 34\% (95\% CI=20\%-50\%) and 34\% (95\% CI=20$51 \%$ ) for women and men, respectively (Figures 7 and 8). In women 8 diagnostic signs and tests showed Sp higher than $34 \%$, whereas in men Sp was 34\% for 7 diagnostic signs and tests. The seven best diagnostic signs and tests in women showed 59-90\% Sp whereas those in men showed 53-86\% $\mathrm{Sp}$ in diagnosis of AA (Figure 8).
Diagnostic performance of the DS without leucocytes $\left(D S_{L C-}\right.$ ) in women. The most important predictors of AA in women without LC $(n=697)$ were tenderness, rigidity, guarding, location of pain at diagnosis, and renal tenderness. The significant predictors were used to construct the $\mathrm{DS}_{\mathrm{LC}-}$ formula for AA diagnosis. In practice, the use of the DS formula is relatively simple as shown by the following; 
Table VI. Diagnostic score of male patients $(n=476)$ with leucocyte count $\left(D S_{L C+}\right)$ shown as six different cut-off levels of symptoms, signs and test.

\begin{tabular}{|c|c|c|c|c|c|c|}
\hline Diagnostic score (DS) & Positive endpoint & Negative endpoint & ТP & FN & FP & TN \\
\hline 1. Logistic model with leucocyte count $\mathrm{DS}_{\mathrm{LC}+}$ VII & Appendicitis & Other diagnosis of acute abdominal pain & 130 & 3 & 111 & 232 \\
\hline 2. Logistic model with leucocyte count $\mathrm{DS}_{\mathrm{LC}+}$ VIII & Appendicitis & Other diagnosis of acute abdominal pain & 128 & 5 & 90 & 253 \\
\hline 3. Logistic model with leucocyte count $\mathrm{DS}_{\mathrm{LC}+} \mathrm{IX}$ & Appendicitis & Other diagnosis of acute abdominal pain & 125 & 8 & 69 & 274 \\
\hline 4. Logistic model with leucocyte count $\mathrm{DS}_{\mathrm{LC}+} \mathrm{X}$ & Appendicitis & Other diagnosis of acute abdominal pain & 118 & 15 & 40 & 303 \\
\hline 5. Logistic model with leucocyte count $\mathrm{DS}_{\mathrm{LC}+} \mathrm{XI}$ & Appendicitis & Other diagnosis of acute abdominal pain & 109 & 24 & 20 & 323 \\
\hline 6. Logistic model with leucocyte count $\mathrm{DS}_{\mathrm{LC}+} \mathrm{XII}$ & Appendicitis & Other diagnosis of acute abdominal pain & 109 & 8 & 20 & 274 \\
\hline
\end{tabular}

TP, True positive; FN, false negative; FP, false positive; TN, true negative. Cut-off levels: DS I=-2.8, DS II=-2.3, DS III=-1.74, DS IV=-0.9, DS $\mathrm{V}=-0.14, \mathrm{VI}=-1.74--0.14$ (follow-up patients $\mathrm{n}=65$ ).

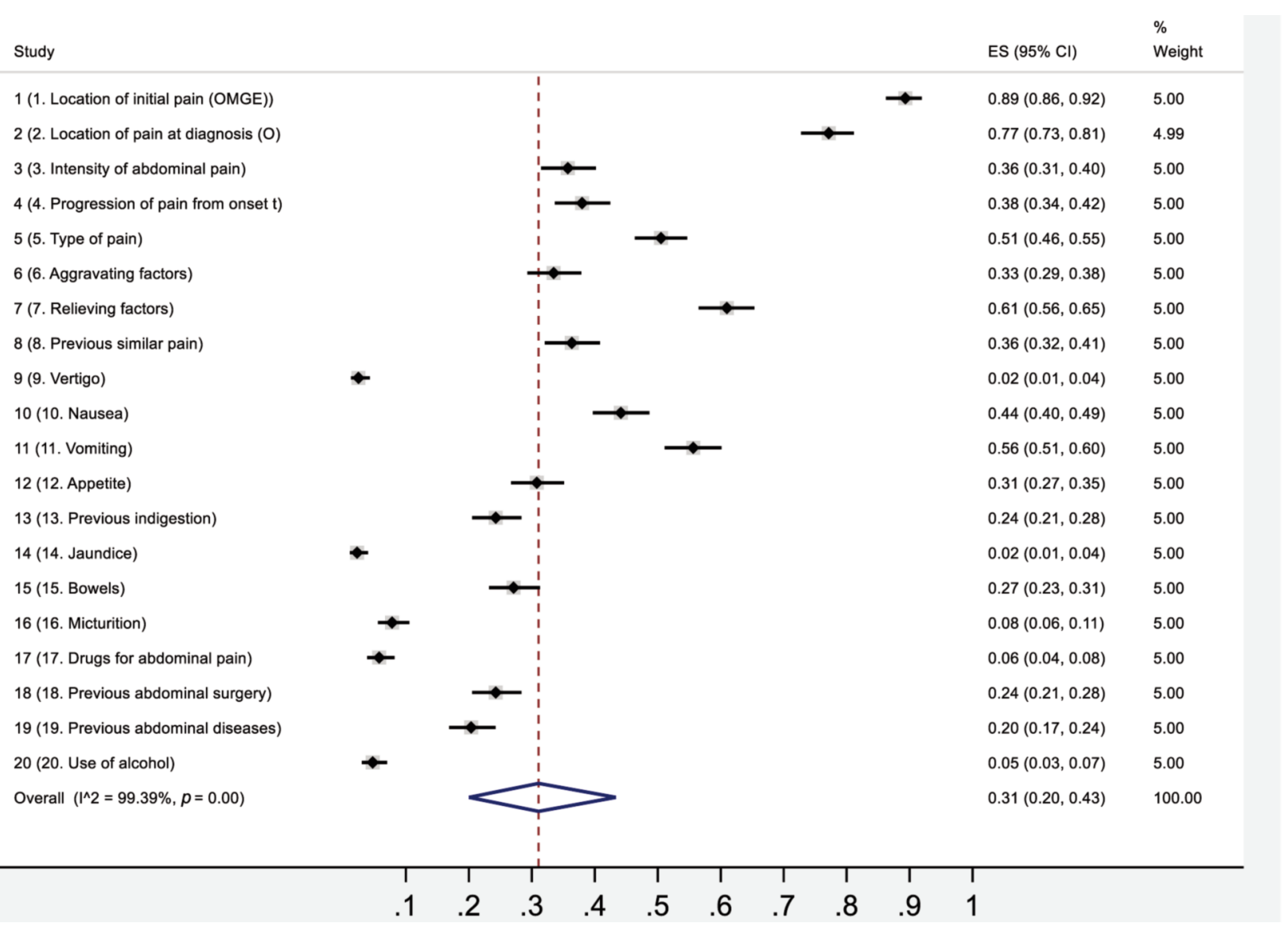

Figure 4. Pooled specificities of the clinical symptoms in acute appendicitis (random-effects model) in men. ES: Estimated specificity; CI: Confidence interval.

" $\mathrm{DS}_{\mathrm{LC}-}=$ a female patient is admitted to the emergency room with abdominal pain; at diagnosis the pain was localized at RLQ (1 point $\times 1.33)$; clinical examination showed RLQ tenderness ( 1 point $\times 2.98)$, rigidity ( 1 point $\times 2.45)$, guarding (1 point $\times 2.08)$ and the renal tenderness test was positive (1 point $\times 0.88)$ ". The best diagnostic performance level for $\mathrm{DS}_{\mathrm{LC}-}$ formula in females $(\mathrm{Se}=93 \%, \mathrm{Sp}=92 \%)$ in $\mathrm{AA}$ diagnosis was reached when the patients with a $\mathrm{DS}_{\mathrm{LC}}$ - value between -2.03 and -0.49 were considered as "grey area" patients $=$ follow-up required before the decision to operate $(n=123)$. The formula was tested at six different cut-off levels to disclose the best diagnostic performance in women (Figures 9 and 10). The pooled overall Se and $\mathrm{Sp}$ of these six $\mathrm{DS}_{\mathrm{LC}-}$ formulas were $88 \%(95 \% \mathrm{CI}=83-92 \%)$ and $89 \%$ 


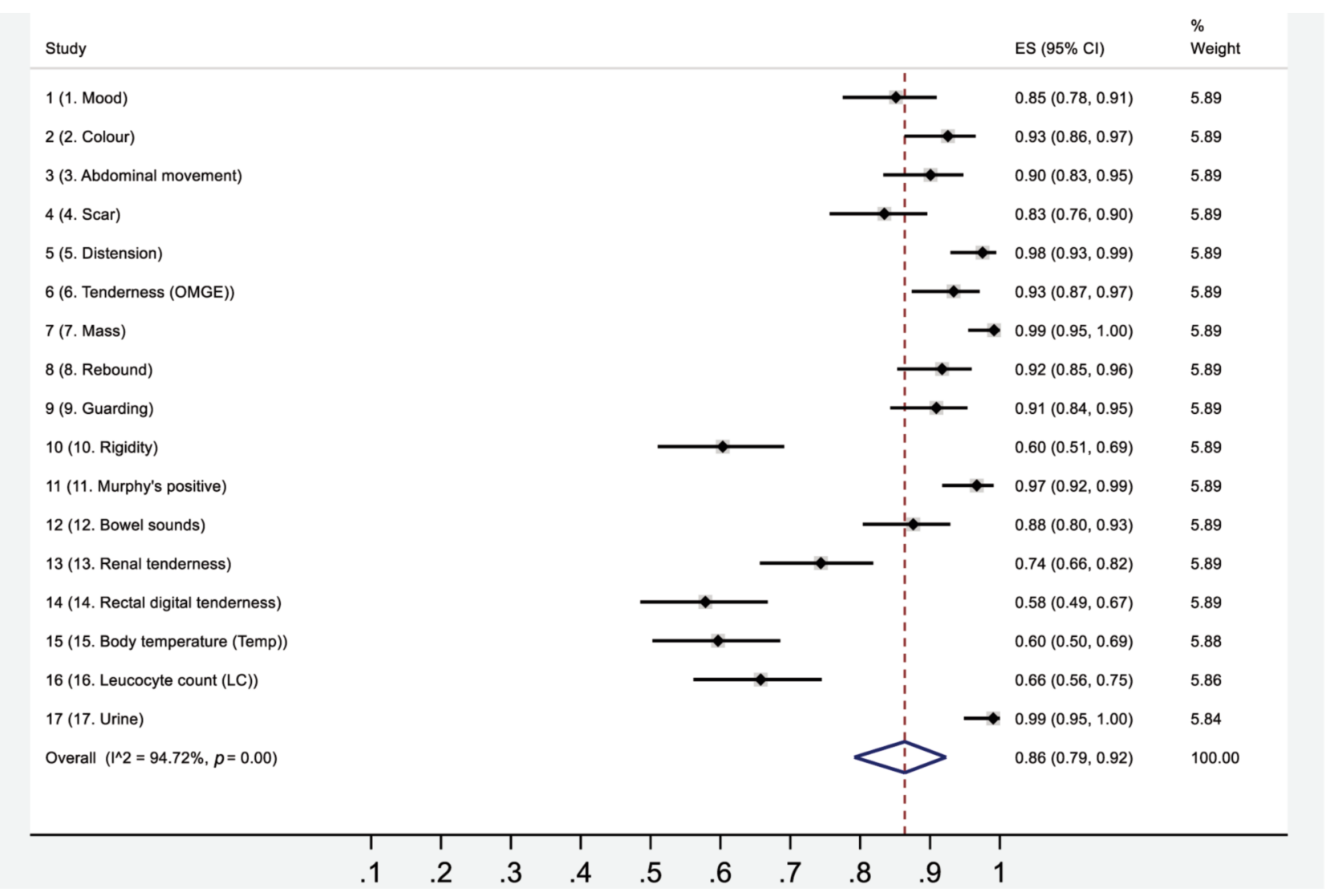

Figure 5. Pooled sensitivities of the clinical signs and tests in acute appendicitis (random-effects model) in women. ES: Estimated sensitivity; CI: Confidence interval.

(95\% CI=84-94\%), respectively (Figures 9 and 10). Three of these formulas showed $\mathrm{Se}>88 \%$ and four formulas had $\mathrm{Sp}$ $>89 \%$. At the best diagnostic $\mathrm{DS}_{\mathrm{LC}-}$ formula in women (formula DS VI, Figure 9 and 10) showed Se of 93\% (95\% $\mathrm{CI}=87-97 \%)$ and $\mathrm{Sp}$ of $92 \%(95 \% \mathrm{CI}=89-94 \%)$.

Diagnostic performance of the DS with leucocytes in women $\left(D S_{L C+}\right)$. Similar as for the $D S_{L C-}$ formulas, the significant independent predictors were used to build up the six different $\mathrm{DS}_{\mathrm{LC}+}$ formulas. The pooled overall $\mathrm{Se}$ and $\mathrm{Sp}$ of these six $\mathrm{DS}_{\mathrm{LC}+}$ models in women was $90 \%(95 \% \mathrm{CI}=85-95 \%)$ and $85 \%$ (95\% CI=74-94\%), respectively (Figures 11 and 12). Four formulas showed $\mathrm{Se}>90 \%$ and four formulas Sp over $85 \%$. The $\mathrm{DS}_{\mathrm{LC}+}$ formula (formula DS XII, Figures 11 and 12) showed $\mathrm{Se}$ of $93 \%(95 \% \mathrm{CI}=87-97 \%)$ and $\mathrm{Sp}$ of $91 \%$ (95\% CI=88-94\%) (Figures 11 and 12).

Diagnostic performance of the DS without leucocytes ( $\left.D S_{L C-}\right)$ in men. The most important predictors of AA in male patients without LC $(n=636)$ were location of pain at diagnosis, previous abdominal surgery, tenderness, rebound, rigidity, guarding and body temperature $\left(\mathrm{DS}_{\mathrm{LC}-}\right.$ formula is shown in patients and methods chapter). In male patients $\mathrm{DS}_{\mathrm{LC}-}$ formula model reached Se of $95 \%$ with $\mathrm{Sp}$ of $89 \%$ when the male patients with DS value between -2.00 and -0.48 were considered as "grey area" patients=follow-up required before the decision to operate $(n=75)$. The $\mathrm{DS}_{\mathrm{LC}-}$ formula was tested at six different cut-off levels to find the best diagnostic performance for AA in men (Figures 13 and 14). The pooled overall Se and $\mathrm{Sp}$ of these six $\mathrm{DS}_{\mathrm{LC}-}$ formulas were $94 \%(95 \%$ $\mathrm{CI}=90-96 \%)$ and $79 \%(95 \% \mathrm{CI}=68-88 \%)$, respectively (Figures 13 and 14). Four of these formulas showed $\mathrm{Se}>94 \%$ and three formulas had $\mathrm{Sp}>79 \%$. At the best diagnostic $\mathrm{DS}_{\mathrm{LC}-}$ in men (formula DS XI, Figures 13 and 14) showed Se of 95\% (95\% $\mathrm{CI}=89-98 \%)$ and $\mathrm{Sp}$ of $89 \%(95 \% \mathrm{CI}=86-92 \%)$.

Diagnostic performance of the DS with leucocytes in men $\left(D S_{L C+}\right)$. The pooled overall Se and $\mathrm{Sp}$ of the six $\mathrm{DS}_{\mathrm{LC}+}$ formulas in men was $93 \%(95 \% \mathrm{CI}=88-96 \%)$ and $84 \%(95 \%$ $\mathrm{CI}=74-92 \%$ ), respectively (Figures 15 and 16). Four formulas showed $\mathrm{Se}>93 \%$ and three formulas had $\mathrm{Sp}>84 \%$. The best diagnostic $\mathrm{DS}_{\mathrm{LC}+}$ formula in men (formula DS XII, Figures 15 and 16) showed Se of 93\% (95\% CI=87-97\%) and $\mathrm{Sp}$ of $93 \%$ (95\% CI=90-96\%) (Figures 15 and 16). 


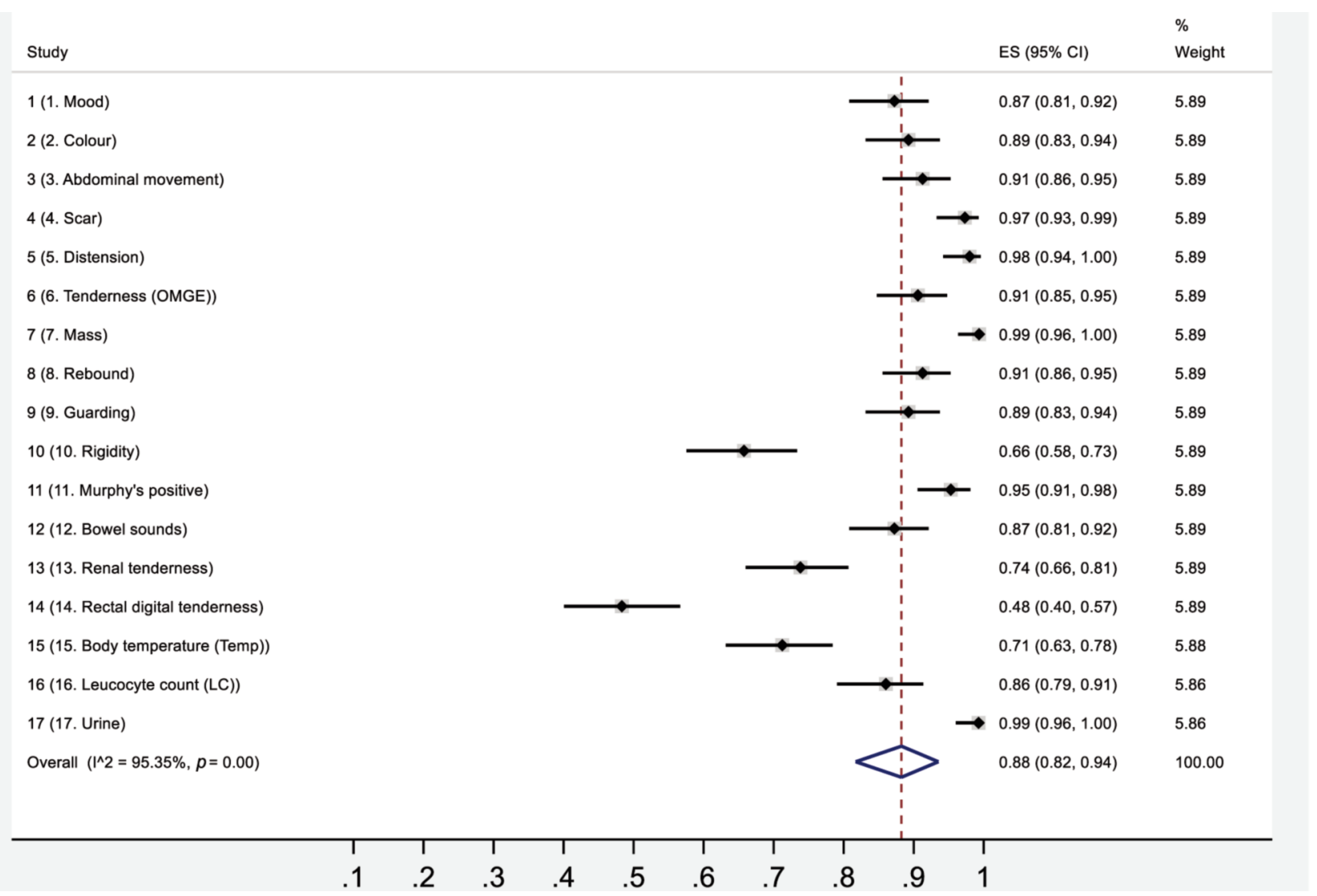

Figure 6. Pooled sensitivities of the clinical signs and tests in acute appendicitis (random-effects model) in men. ES: Estimated sensitivity; CI: Confidence interval.

HSROC analyses and empirical Bayes (EB) estimates in both genders. STATA (metandiplot algorithm) was used to draw the HSROC curves and EB estimates to visualise the comparison of the pooled overall diagnostic performance of the different DS formulas in detecting AA in women (Figures 17 and 18) and men (Figures 19 and 20). In the HSROC analysis in women, there is no statistically significant difference between the $\mathrm{DS}_{\mathrm{LC}-}$ and $\mathrm{DS}_{\mathrm{LC}+}$ formulas, with $\mathrm{AUC}=0.949(95 \% \mathrm{CI}=0.921-0.968)$ and $\mathrm{AUC}=0.953(95 \%$ $\mathrm{CI}=0.923-0.969)(p=0.631, \mathrm{ROC}$ comparison test $)$. The same is true with the HSROC analysis in men, with no difference between the $\mathrm{DS}_{\mathrm{LC}-}$ and $\mathrm{DS}_{\mathrm{LC}+}$ formulas, with $\mathrm{AUC}=0.948$ (95\% CI $=0.920-0.964)$ and $\mathrm{AUC}=0.956(95 \% \mathrm{CI}=0.930$ $0.969)$ ( $p=0.321$, ROC comparison test).

\section{Discussion}

We studied patients presenting with AAP as a part of the survey by the OMGE Committee (4-8) and estimated the diagnostic accuracy of a combined history-taking, clinical examination and laboratory testing in verified AA (5), NSAP (5), acute small bowel obstruction (7) and in acute renal stone disease (8). Although there are several different DS systems designed for AAP diagnosis $(5,9-15)$ and the international guidelines recommend routine diagnostic scoring to improve the diagnosis of AA $(16,17)$, a debate continues on the shortcomings of the specific DS models in women and men with AAP. Thus, it was appropriate to compare the performance of our gender-specific DS models in both genders, using DSs with and without LC.

Comparison of the symptoms, signs and laboratory tests in women vs. men. There was no gender-specific difference in the clinical symptoms, since the five diagnostic symptoms with highest diagnostic accuracy were identical in women and men (vertigo, jaundice, micturition, drugs for abdominal pain and use of alcohol), showing 95-100\% Se in diagnosis of AA. The same applies to gender-specific difference in Sp, the five most relevant symptoms being identical in both genders (location of initial pain, location of pain at diagnosis, type of pain, relieving factors and vomiting) presenting with $51-89 \% \mathrm{Sp}$ in diagnosis of AA.

Similarly, there was no significant difference in signs and laboratory test results between women and men with confirmed 


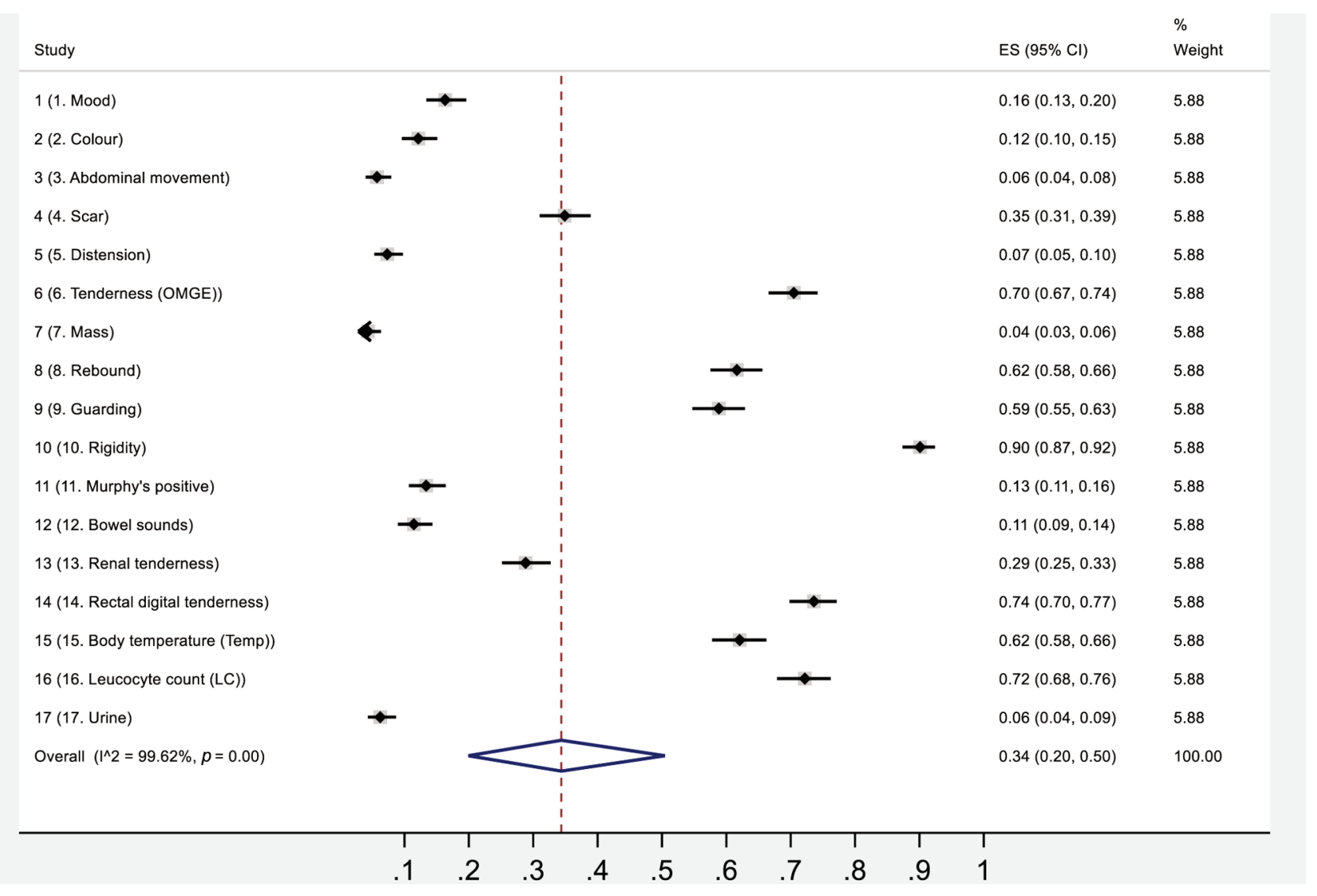

Figure 7. Pooled specificities of the clinical signs and tests in acute appendicitis (random-effects model) in women. ES: Estimated sensitivity; CI: Confidence interval.

AA in their pooled Se, because the five best diagnostic signs and tests were very similar in both genders; women (distension, tenderness, mass, Murphy's sign, urine) and men (scar, distension, mass, Murphy's sign, urine) showing 93-99\% Se in diagnosis of AA. Also, the pooled Sp of the signs and tests in AA detection was equal in both genders.

Female $D S_{L C-}$ and $D S_{L C+}$. Of interest was to assess, whether the addition of LC would give any added value to our DSs, herein performed by comparing the diagnostic accuracy of $\mathrm{DS}_{\mathrm{LC}-}$ and $\mathrm{DS}_{\mathrm{LC}+}$ scores. The present analysis suggests that female patients with $\mathrm{DS}_{\mathrm{LC}-}$ below -2.03 should not be

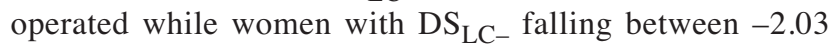
and -0.49 should be followed-up before the final decision. According to our data, only the AAP-women with the $\mathrm{DS}_{\mathrm{LC}-}$ values exceeding -0.49 should be operated without delay. In women whose LC was calculable $(n=575)$ the important predictors of AA were the same as in women without LC, but $\mathrm{LC}$ is added to $\mathrm{DS}_{\mathrm{LC}+}$ formula ( $\mathrm{LC} \geq 10,000 \mu \mathrm{l}$ ) (see the methods for formula details). In women, the highest diagnostic accuracy for $\mathrm{DS}_{\mathrm{LC}+}$ formula $(\mathrm{Se}=93 \%, \mathrm{Sp}=91 \%)$ in AA diagnosis was reached when the patients with $\mathrm{DS}_{\mathrm{LC}+}$ values falling between -2.33 and -0.41 were considered as "grey zone" patients, for whom follow-up was appropriate before the decision to operate $(n=77)$. Taken together, i) the female AAP patients with $\mathrm{DS}_{\mathrm{LC}+}$ value below -2.33 should not be operated, ii) those with $\mathrm{DS}_{\mathrm{LC}+}$ value between -2.33 and -0.41 should be followed-up and iii) all AAP-women with the $\mathrm{DS}_{\mathrm{LC}+}$ value higher than -0.41 should be operated without delay.

Male $D S_{L C-}$ and $D S_{L C+}$. The same considerations can be made among male patients with AAP. Our present data

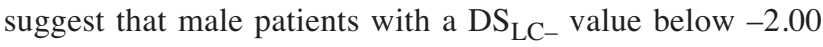
should not be operated. Those men with $\mathrm{DS}_{\mathrm{LC}-}$ values between -2.00 and -0.48 should be followed-up, whereas all those with $\mathrm{DS}_{\mathrm{LC}-}$ values above -0.48 should be operated with no delay. In males with LC available $(n=476)$, the AA predictors were the same as earlier but added with the LC and rectal digital examination. When the men with a $\mathrm{DS}_{\mathrm{LC}-}$ value between -1.74 and -0.14 were considered equivocal $\left(\mathrm{n}=67\right.$, follow-up required), the $\mathrm{Se}$ of this $\mathrm{DS}_{\mathrm{LC}}$ in $\mathrm{AA}$ was $93 \%$, with a Sp of $93 \%$ and an efficiency of $93 \%$. As to the males and $\mathrm{DS}_{\mathrm{LC}+}$ the present analysis implicates that the 


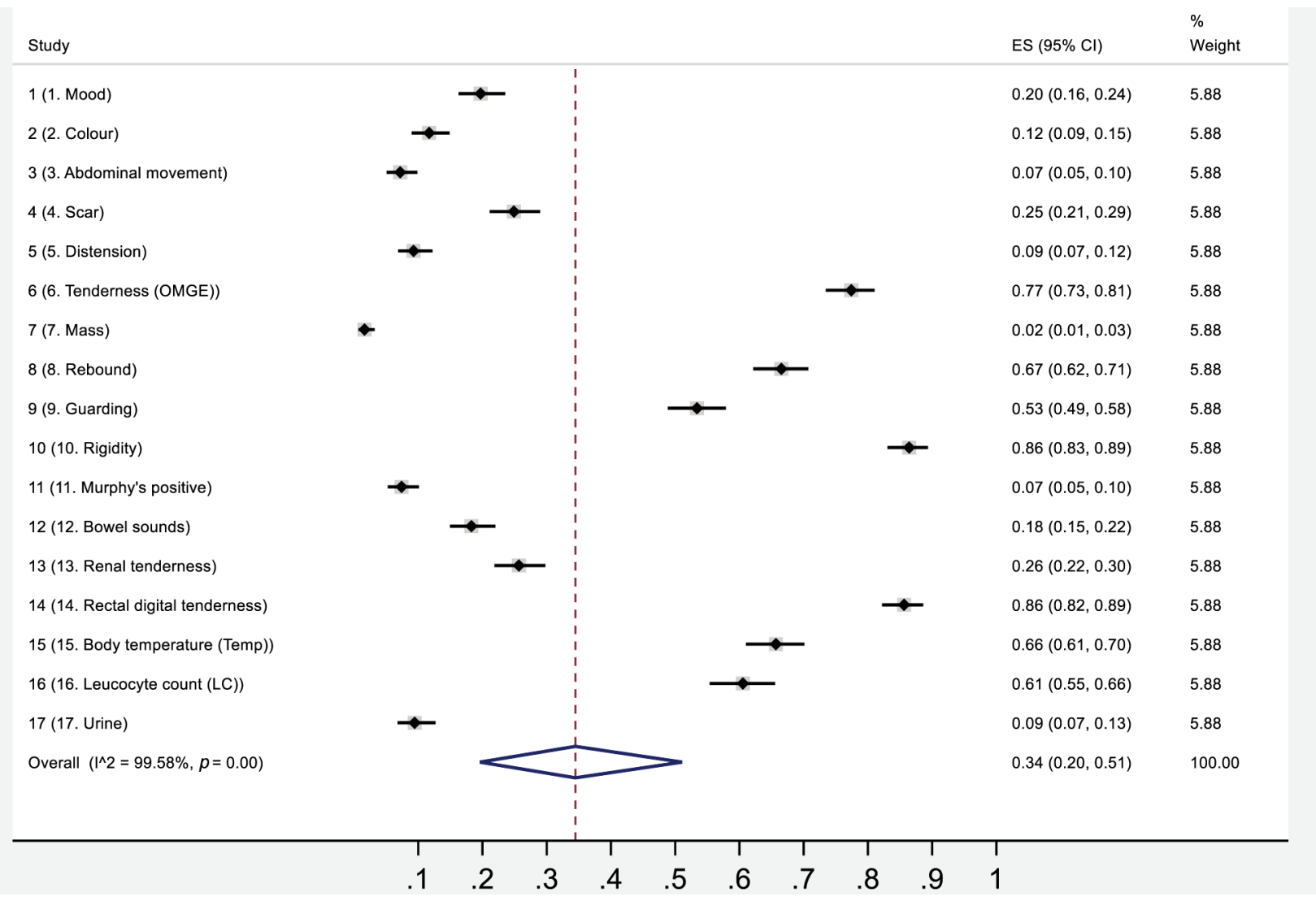

Figure 8. Pooled specificities of the clinical signs and tests in acute appendicitis (random-effects model) in men. ES: Estimated sensitivity; CI: Confidence interval.

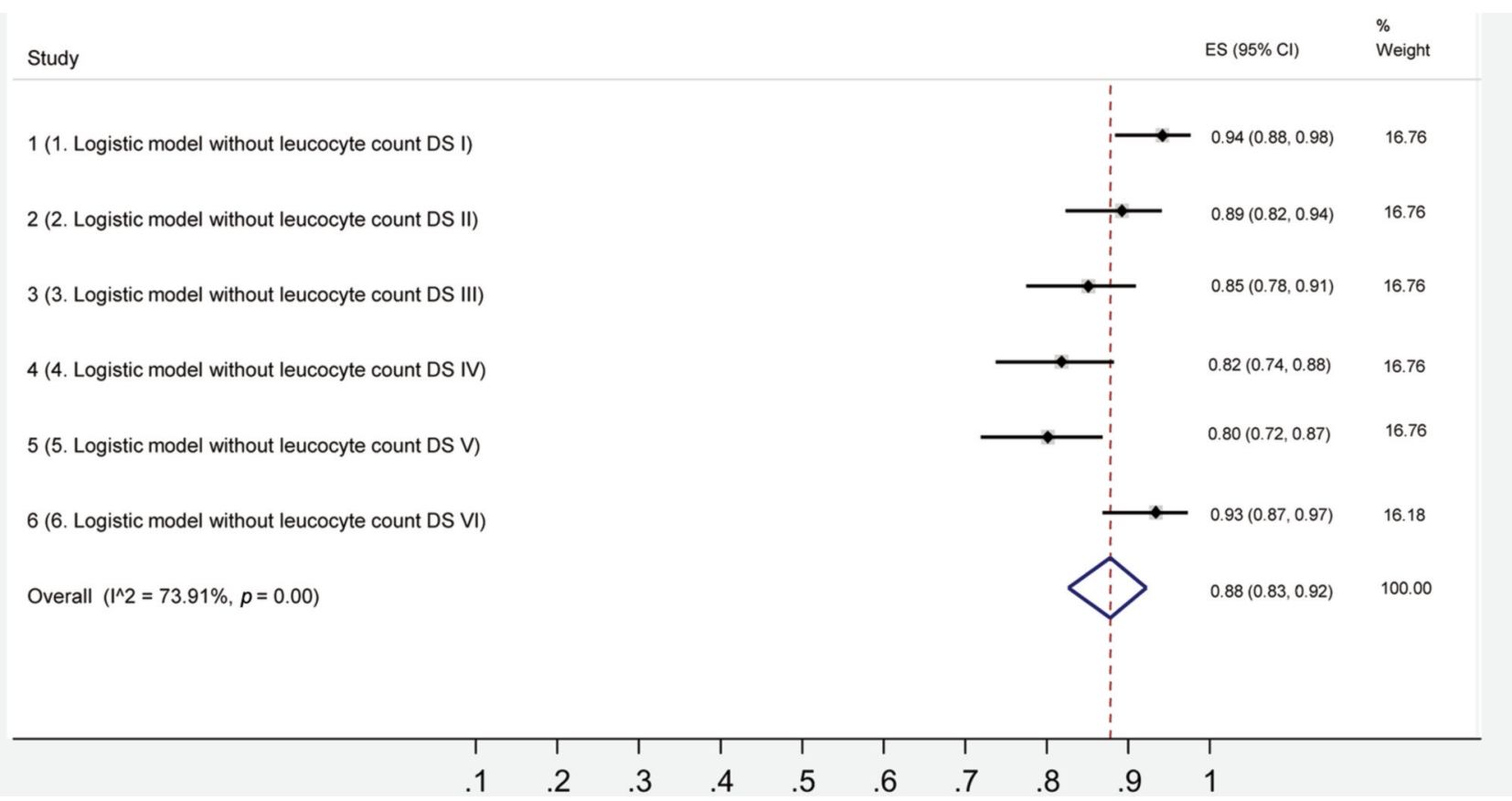

Figure 9. Sensitivities of diagnostic scores without leucocyte count $\left(D S_{L C-}\right)$ in women at six different cut-off levels (DS I-VI). 


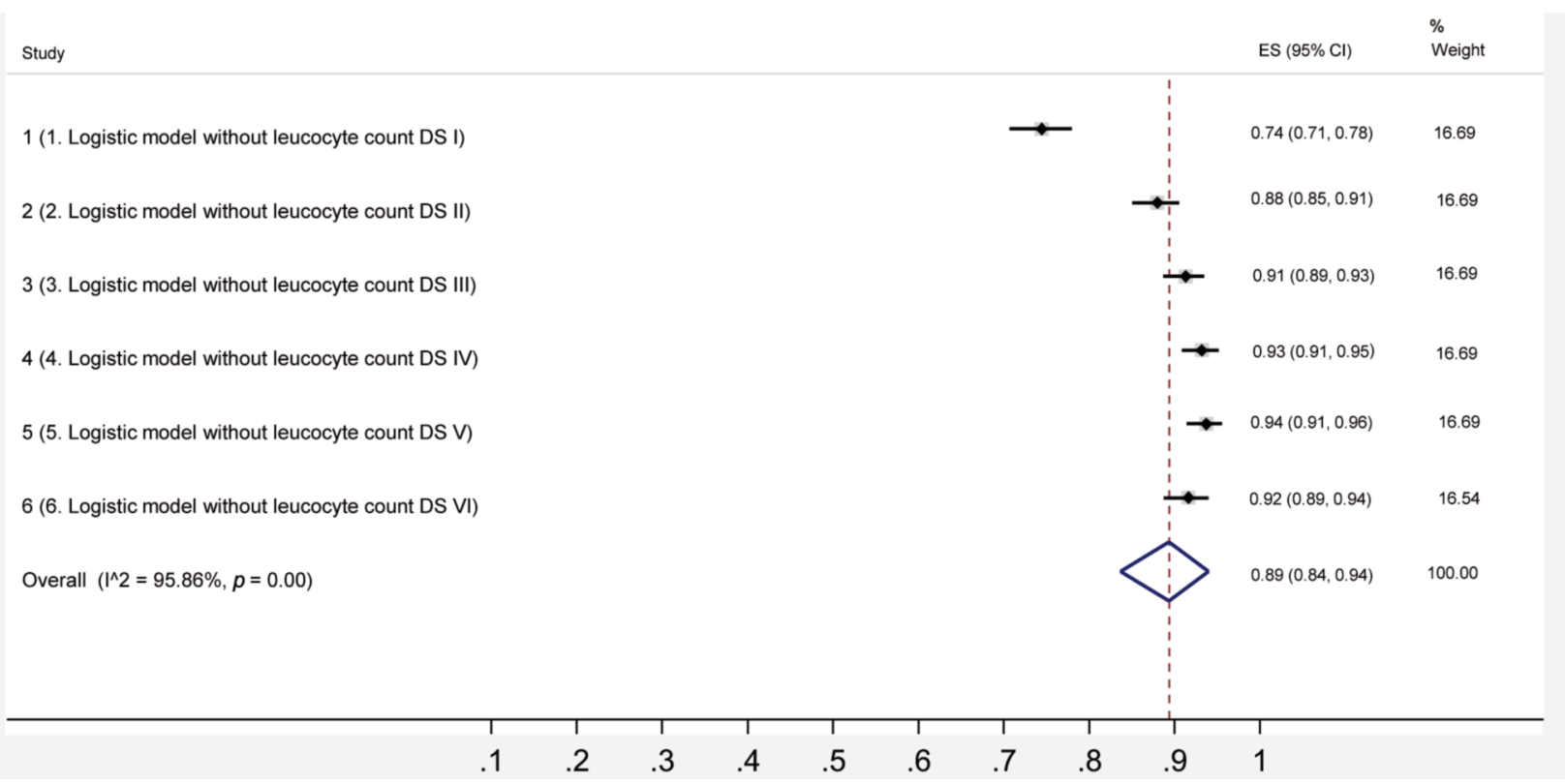

Figure 10. Specificities of diagnostic scores without leucocyte count (DSLC-) in women at six different cut-off levels (DS I-VI).

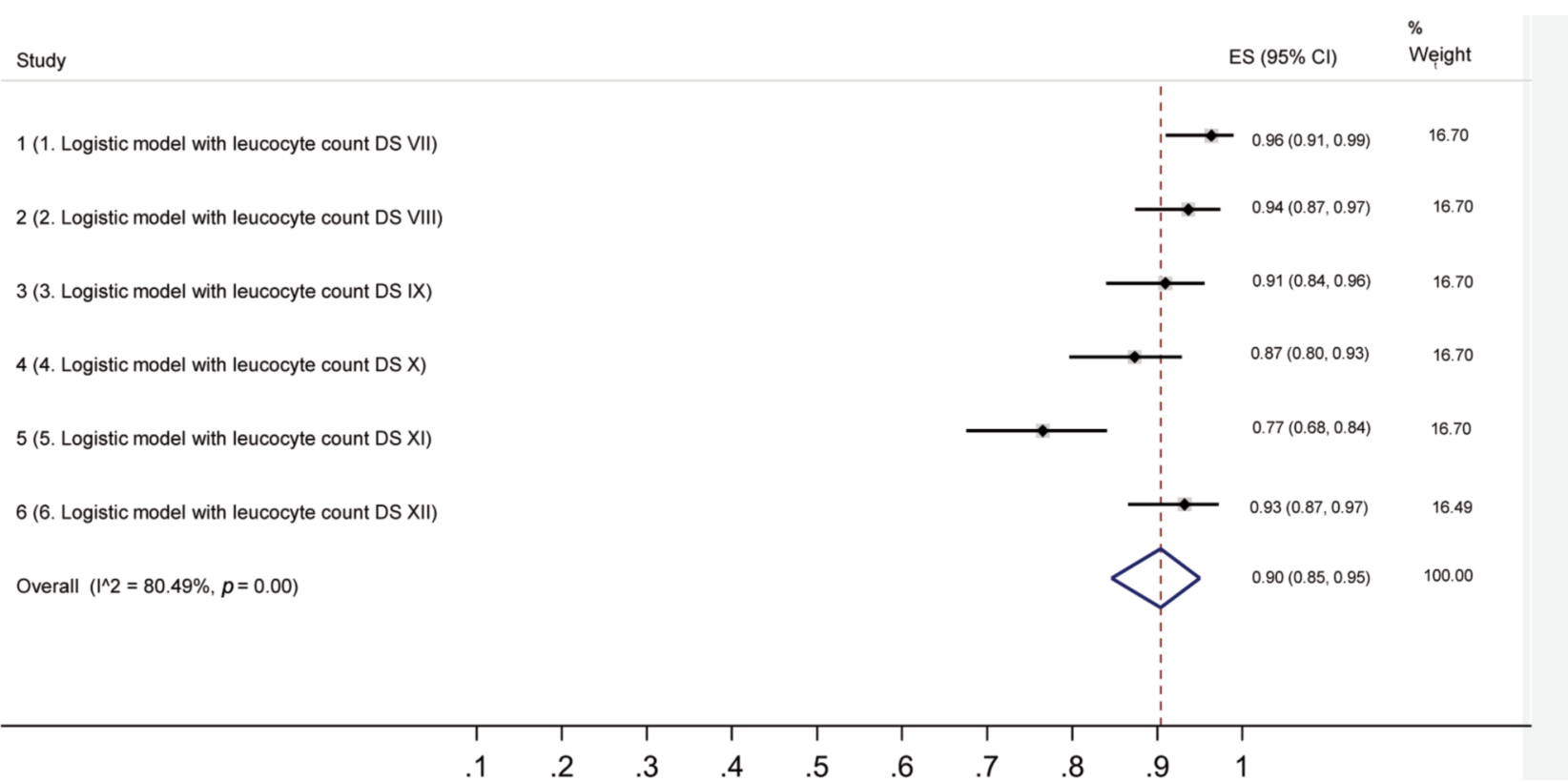

Figure 11. Sensitivities of diagnostic scores with leucocyte count (DSLC+) in women at six different cut-off levels (DS I-VI).

patients with a $\mathrm{DS}_{\mathrm{LC}+}$ value below -1.74 should not be operated, while those with $\mathrm{DS}_{\mathrm{LC}+}$ values between -1.74 and -0.14 could be safely followed-up. This leaves only the male patients with $\mathrm{DS}_{\mathrm{LC}+}$ values above -0.14 , who should be immediately operated.

A right iliac fossa tenderness (RIFT) Study Group in UK suggested that female patients $(272 / 964,28.2 \%)$ with AAP were more than twice as likely as males to undergo surgery with histologically normal appendix as a result (i.e. negative appendectomy, FP $) \quad(120 / 993,12,1 \%) \quad(\mathrm{RR}=2.33,95 \%$ $\mathrm{CI}=1.92-2.84, p<0.001)$. Although several AA risk scorings (5, 9-15) demonstrate different predictive factors for AA diagnosis, as far as we know, only the RIPASA scoring provides gender-specific data (19). The present study is the 


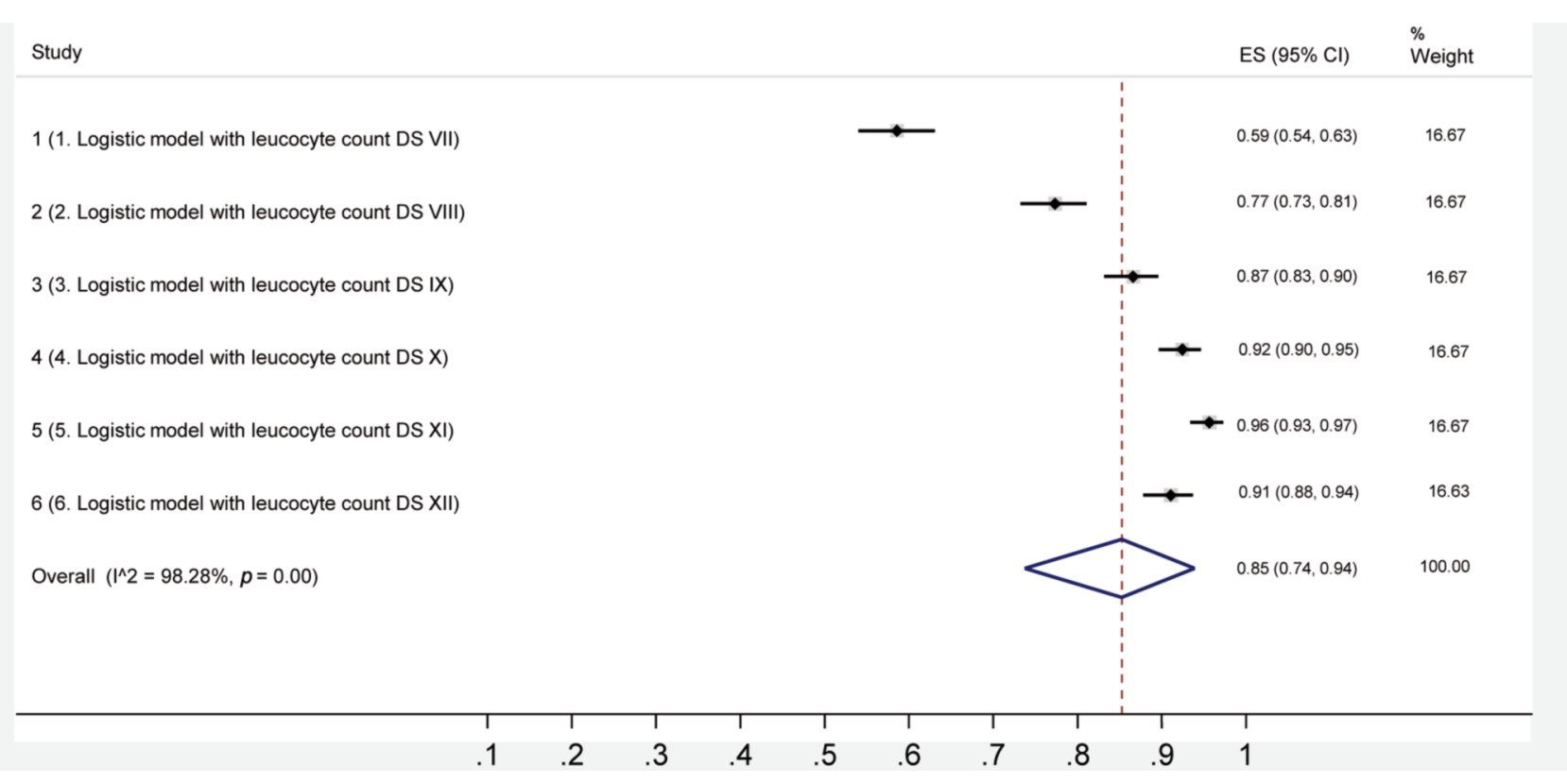

Figure 12. Specificities of diagnostic scores with leucocyte count (DSLC+) in women at six different cut-off levels (DS VII-XII).

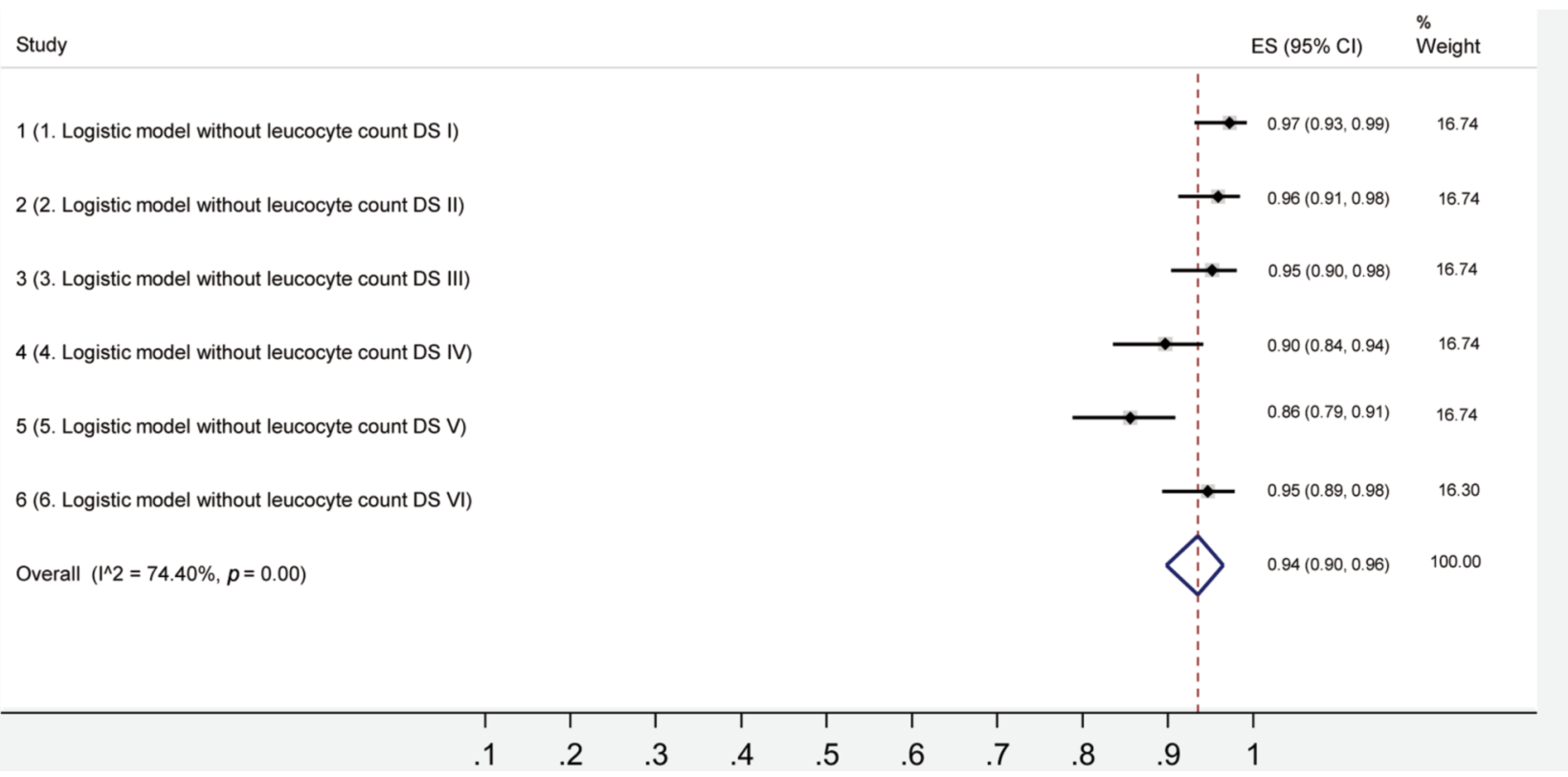

Figure 13. Sensitivities of diagnostic scores without leucocyte count (DSLC-) in men at six different cut-off levels (DS I-VI).

second to provide such data, while reporting the diagnostic performance of the $\mathrm{DS}_{\mathrm{LC}-}$ and $\mathrm{DS}_{\mathrm{LC}+}$ models in both genders: The aim was to elaborate the optimal combination of symptoms, signs and tests in the DS formulas with and without LC and using six different combinations $\left(\mathrm{DS}_{\mathrm{LC}-}\right.$ and $\mathrm{DS}_{\mathrm{LC}+}$ ) as diagnostic predictors of AA. Our DS is in line with APPEND score (20) that the LC testing was not an important predictor of AA diagnosis, while APPEND score does not account for the significance of gender in AA. Alvarado (9) and Appendicitis Inflammatory Response (21) scores emphasize LC analysis as a significant predictor of AA diagnosis and APPEND score identified neutrophil percent and neutrophil/ lymphocyte ratio as important predictors of AA. AA diagnosis strategies in the future may include early markers of 


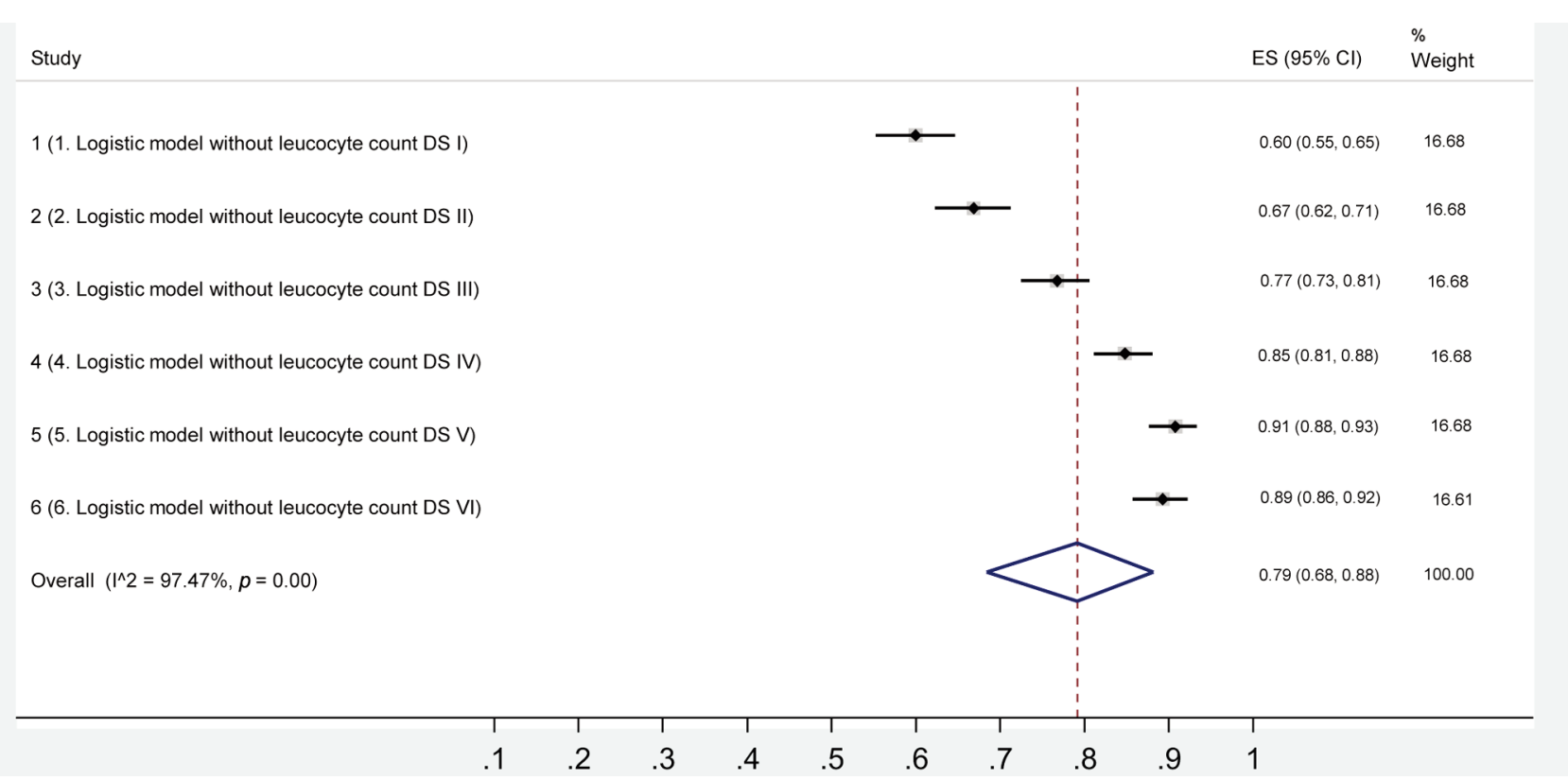

Figure 14. Specificities of diagnostic scores with leucocyte count (DSLC-) in men at six different cut-off levels (DS I-VI).

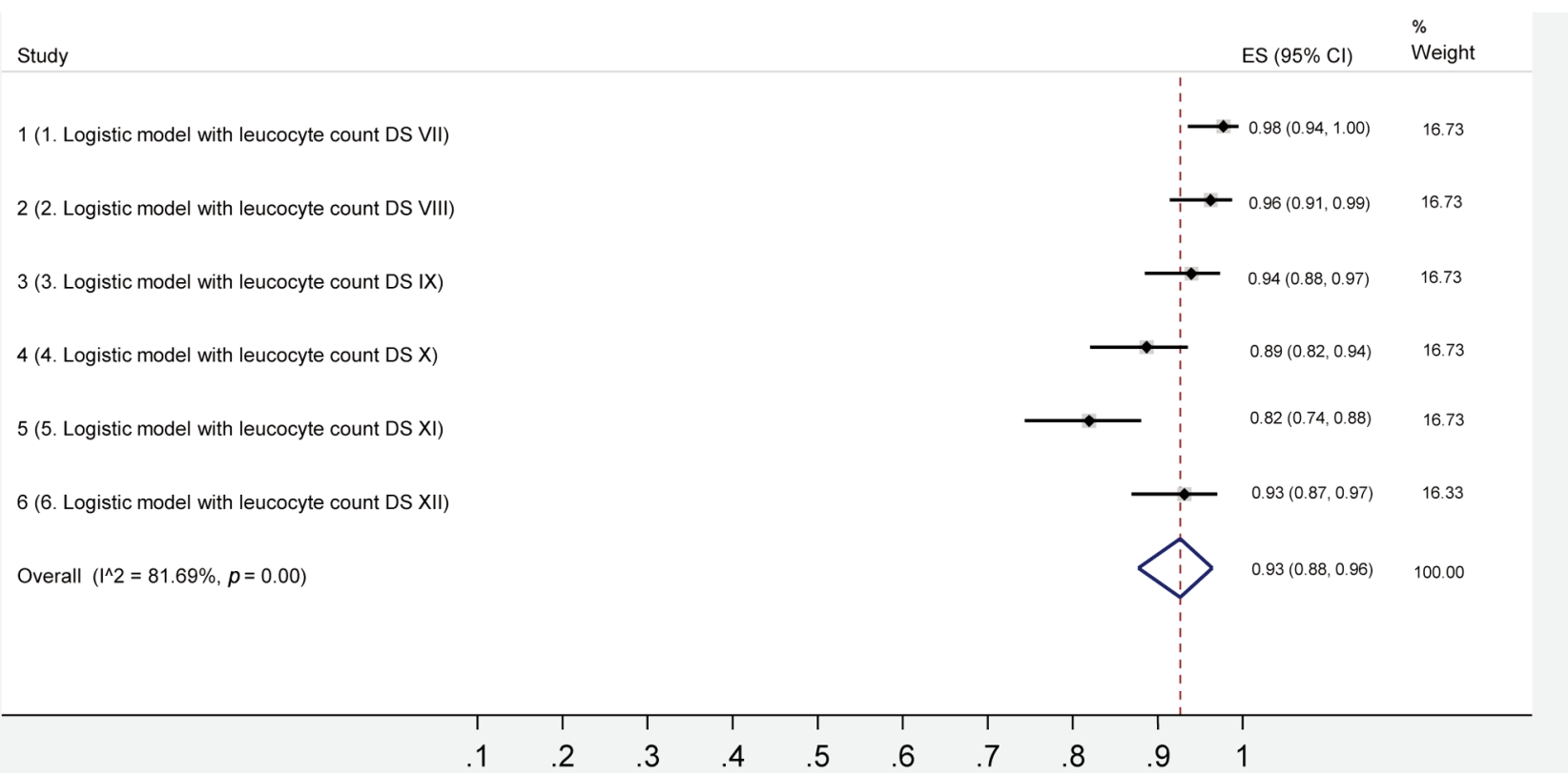

Figure 15. Sensitivities of diagnostic scores with leucocyte count (DSLC+) in men at six different cut-off levels (DS VII-XII).

inflammation e.g. interleukin 6 (IL-6) blood levels of which were shown to increase even 3-fold from the reference levels in perforated AA (22), suggesting that IL-6 analysis may be useful in predicting AA complication risk. Although the IL-6 analysis is promising, the current antigen test method precludes its use as a rapid test in AA so far $(23,24)$.

\section{Conclusion}

In conclusion, our gender-specific DS reached very high AUC values (0.948-0.956) in both genders, and using the ROC comparison test, there was no statistically significant difference in the AUC values of $\mathrm{DS}_{\mathrm{LC}-}$ and $\mathrm{DS}_{\mathrm{LC}+}$ between 


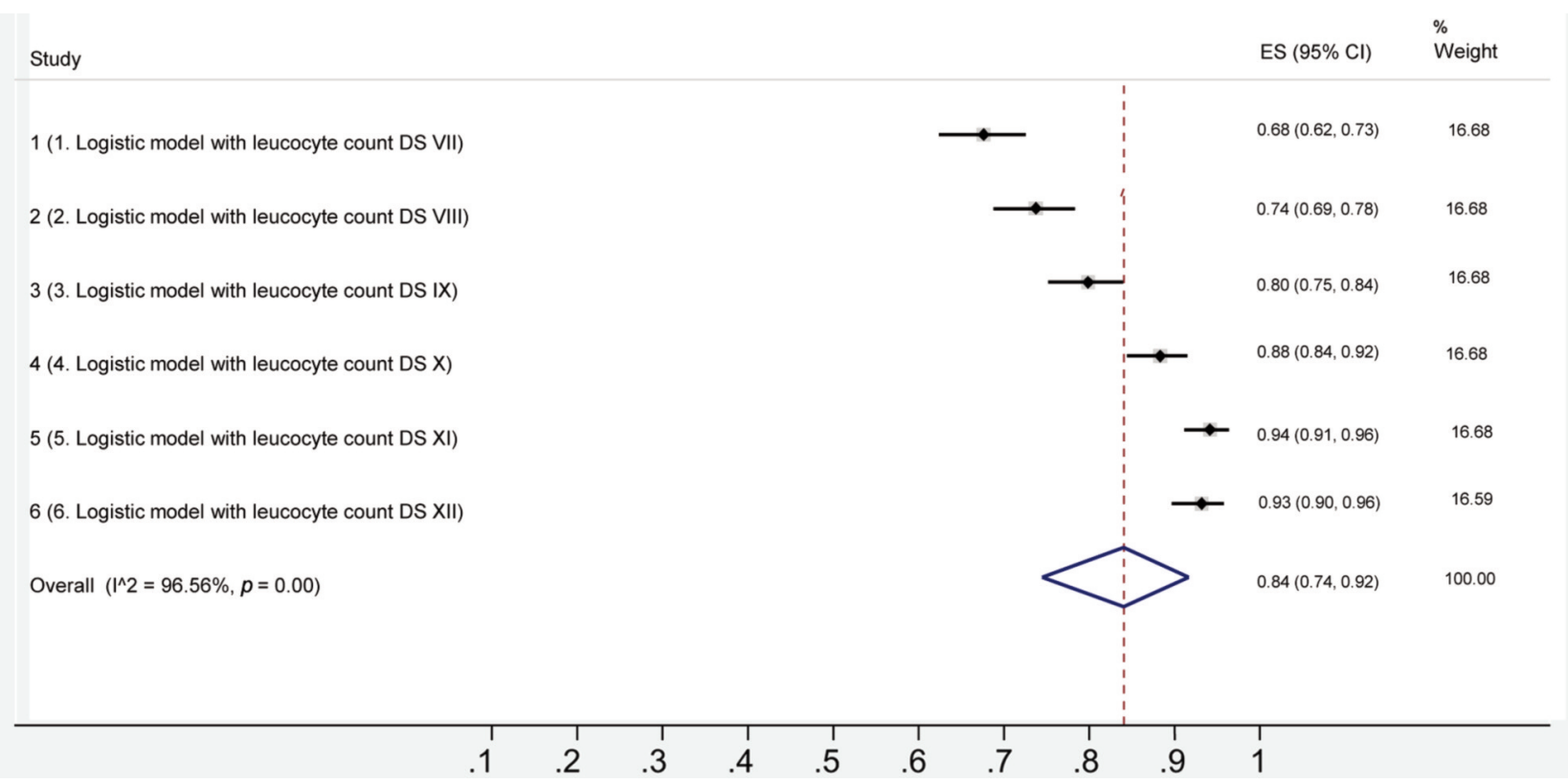

Figure 16. Specificities of diagnostic scores with leucocyte count (DSLC-) in men at six different cut-off levels (DS VII-XII).

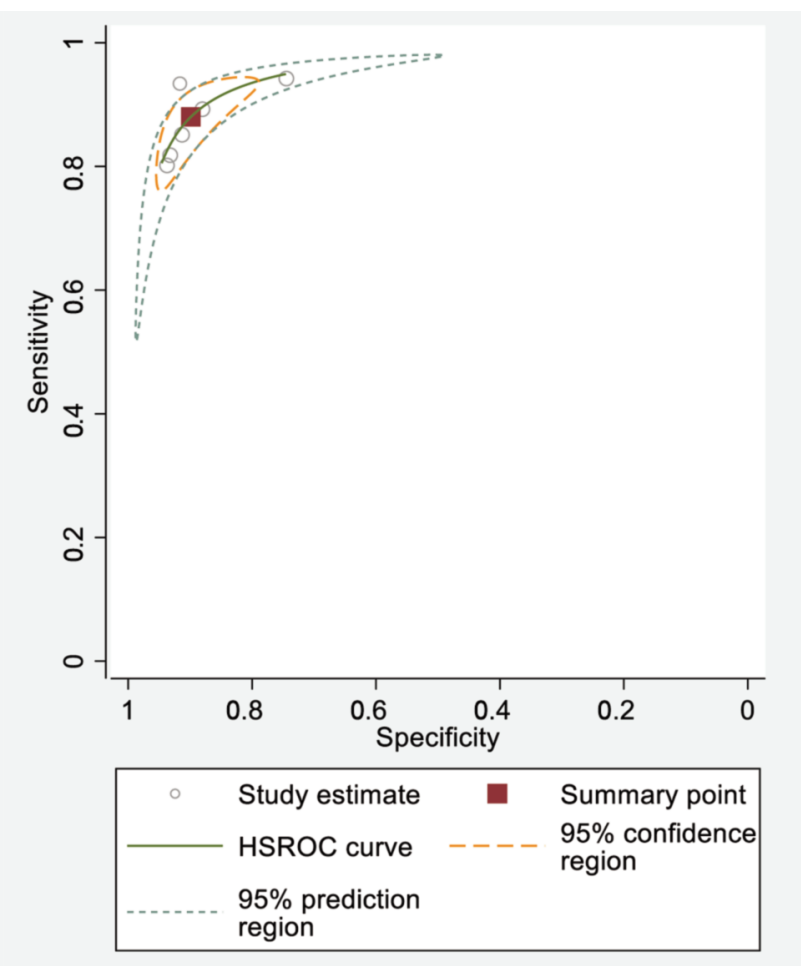

Figure 17. Hierarchical summary receiver operating characteristic (HSROC) curve of the six DSLC- in women.

women and men. Kularatna et al. (15) reviewed available DS formulas in AA and showed between $84 \%$ and $96 \%$ AUC values in AA diagnosis. Although, weakness of the

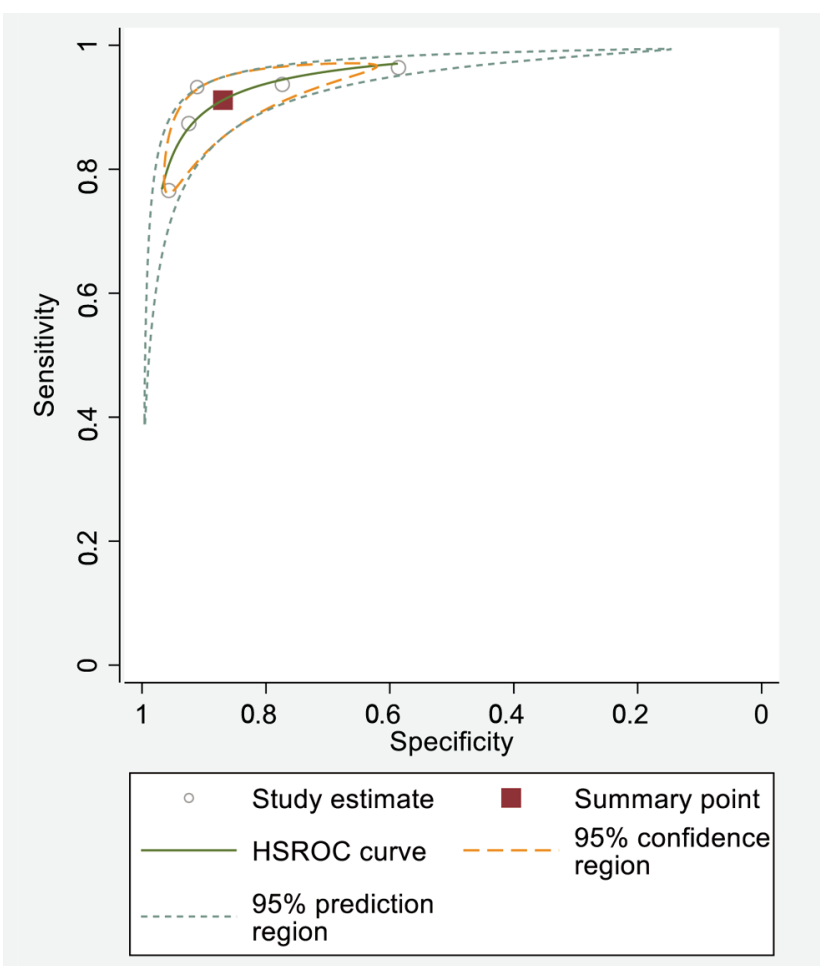

Figure 18. Hierarchical summary receiver operating characteristic (HSROC) curve of the six DSLC+ in women.

meta-analysis is heterogeneity and quality of included studies, it seems that the Tzanakis score (13) with ultrasound (US) and inflammatory markers reached the 


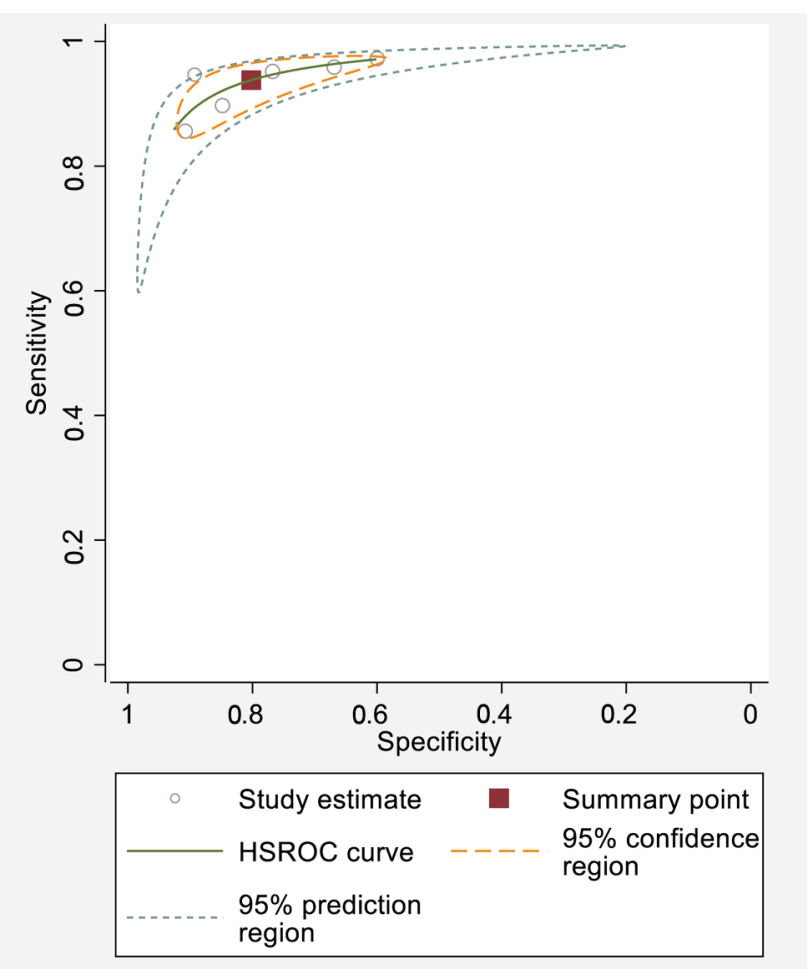

Figure 19. Hierarchical summary receiver operating characteristic (HSROC) curve of the six DSLC- in women.

highest diagnostic performance with $96 \%$ AUC in AA. This is equal with the AUC values obtained in the present study. However, the advantage of our DS is that this scoring does not need US or LC analysis to reach a high diagnostic accuracy in AA.

\section{Conflicts of Interest}

The Authors report no conflicts of interest or financial ties to disclose. The Authors alone are responsible for the content and writing of this article.

\section{Authors' Contributions}

All Authors have met all of the following four criteria: 1 . Substantial contributions to the conception or design of the work or the acquisition, analysis, or interpretation of data for the work. 2. Drafting the work or revising it critically for important intellectual content. 3. Final approval of the version to be published. 4. Agreement to be accountable for all aspects of the work in ensuring that questions related to the accuracy or integrity of any part of the work are appropriately investigated and resolved.

\section{Acknowledgements}

The study was funded by the Päivikki ja Sakari Sohlberg Foundation.

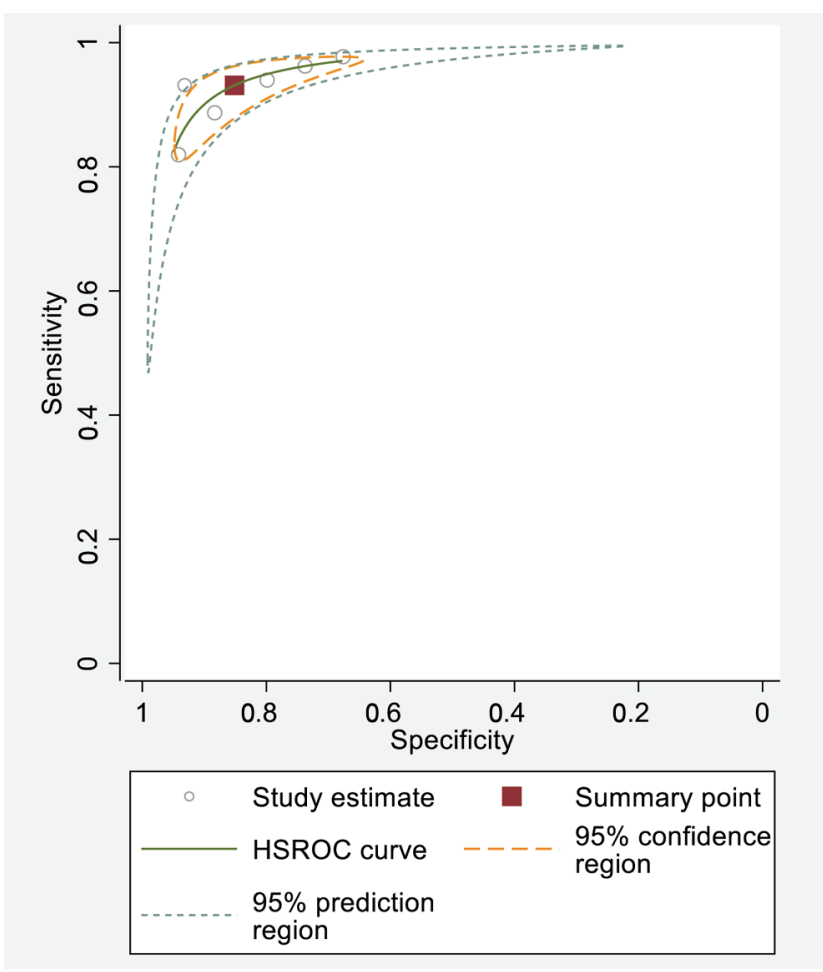

Figure 20. Hierarchical summary receiver operating characteristic (HSROC) curve of the six DSLC+ in men .

\section{References}

1 Ferris M, Quan S, Kaplan BS, Molodecky N, Ball CG, Chernoff GW, Bhala N, Ghosh S, Dixon E, Ng S and Kaplan GG: The global incidence of appendicitis: a systematic review of population-based studies. Ann Surg 266: 237-241, 2017. PMID: 28288060. DOI: $10.1097 /$ SLA.0000000000002188

2 Meklin J, Eskelinen M, Syrjänen K and Eskelinen M: Leucocyte count does not improve the diagnostic performance of a diagnostic score (DS) in distinguishing acute appendicitis (AA) from nonspecific abdominal pain (NSAP). In Vivo, 2020 In press.

3 A Bhangu, RIFT Study Group on behalf of the West Midlands Research Collaborative: Evaluation of appendicitis risk prediction models in adults with suspected appendicitis. Br J Surg 107: 7386, 2020. PMID: 31797357. DOI: 10.1002/bjs.11440

4 Dombal FT de: The OMGE acute abdominal pain survey. Progress report 1986. Scand J Gastroenterol 23(Suppl. 144): 3542, 1988. PMID: 3043646.

5 Eskelinen M, Ikonen J and Lipponen P: A computer-based diagnostic score to aid in diagnosis of acute appendicitis. Theor Surg 7: 86-90, 1992.

6 Eskelinen M and Lipponen P: Usefulness of history-taking in non-specific abdominal pain: a prospective study of 1333 patients with acute abdominal pain in Finland. In Vivo 26: 335 339, 2012. PMID: 22351680.

7 Eskelinen M, Ikonen J and Lipponen P: Contributions of historytaking, physical examination, and computer assistance to diagnosis of acute small-bowel obstruction. A prospective study 
of 1333 patients with acute abdominal pain. Scand $\mathrm{J}$ Gastroenterol 29: 715-721, 1994. PMID: 7973431. DOI: $10.3109 / 00365529409092499$

8 Eskelinen M, Ikonen J and Lipponen P: Usefulness of historytaking, physical examination and diagnostic scoring in acute renal colic. Eur Urol 34: 467-473, 1998. PMID: 9831787. DOI: $10.1159 / 000019785$

9 Alvarado A: A practical score for the early diagnosis of acute appendicitis. Ann Emerg Med 15: 557-564, 1986. PMID: 3963537. DOI: 10.1016/s0196-0644(86)80993-3

10 Ohmann C, Franke C and Yang Q: Clinical benefit of a diagnostic score for appendicitis: results of a prospective interventional study. German Study Group of Acute Abdominal Pain. Arch Surg 134: 993-996, 1999. PMID: 10487595. DOI: 10.1001/archsurg.134.9.993

11 Sitter H, Hoffmann S, Hassan I and Zielke A: diagnostic score in appendicitis. validation of a diagnostic score (Eskelinen score) in patients in whom acute appendicitis is suspected. Langenbecks Arch Surg 389: 213-218, 2004. PMID: 14624293. DOI: $10.1007 / \mathrm{s} 00423-003-0436-9$

12 Lintula H, Pesonen E, Kokki H, Vanamo K and Eskelinen M: A diagnostic score for children with suspected appendicitis. Langenbecks Arch Surg 390: 164-170, 2005. PMID: 15723233. DOI: $10.1007 / \mathrm{s} 00423-005-0545-8$

13 Tzanakis NE, Efstathiou SP, Danulidis K, Rallis GE, Tsioulos DI, Chatzivasiliou, Peros G and Nikiteas NI: A new approach to accurate diagnosis of acute appendicitis. World J Surg 29: 1151-1156, 2005. PMID: 16088420. DOI: 10.1007/s00268-0057853-6

14 Frountzas M, Stergios K, Kopsini D, Schizas D, Kontzoglou K and Toutouzas K: Alvarado or RIPASA score for diagnosis of acute appendicitis? A meta-analysis of randomized trials. Int $\mathbf{J}$ Surg 56: 307-314, 2018. PMID: 30017607. DOI: 10.1016/j.ijsu. 2018.07.003

15 Kularatna M, Lauti M, Haran C, MacFater W, Sheikh L, Huang $\mathrm{Y}, \mathrm{McCa}$ ll $\mathrm{J}$ and MacCormick AD: Clinical prediction rules for appendicitis in adults: which is best? World J Surg 41: 17691781, 2017. PMID: 28258458. DOI: 10.1007/s00268-0173926-6

16 Di Saverio S, Birindelli A, Kelly MD, Catena F, Weber DG, Sartelli M, Sugrue M, De Moya M, Gomes CA, Bhangu A, Agresta F, Moore EE, Soreide K, Griffiths E, De Castro S, Kashuk J, Kluger Y, Leppaniemi A, Ansaloni L, Andersson M, Coccolini F, Coimbra R, Gurusamy KS, Campanile FC, Biffl W, Chiara O, Moore F, Peitzman AB, Fraga GP, Costa D, Maier RV, Rizoli S, Balogh ZJ, Bendinelli C, Cirocchi R, Tonini V, Piccinini A, Tugnoli G, Jovine E, Persiani R, Biondi A, Scalea A, Stahel P, Ivatury R, Velmahos G and Andersson R: WSES Jerusalem guidelines for diagnosis and treatment of acute appendicitis. World J Emerg Surg 11: 34, 2016. PMID: 27437029. DOI: $10.1186 / \mathrm{s} 13017-016-0090-5$
17 Gorter RR, Eker HH, Gorter-Stam MA, Abis GS, Acharya A, Ankersmit M, Antoniou SA, Arolfo S, Babic B, Boni L, Bruntink M, van Dam DA, Defoort B, Deijen CL, DeLacy FB, Go PM, Harmsen AM, van den Helder RS, Iordache F, Ket JC, Muysoms FE, Ozmen MM, Papoulas M, Rhodes M, Straatman J, Tenhagen M, Turrado V, Vereczkei A, Vilallonga R, Deelder JD and Bonjer J: Diagnosis and management of acute appendicitis. EAES consensus development conference 2015. Surg Endosc 30: 4668-4690, 2016. PMID: 27660247. DOI: 10.1007/s00464-016-5245-7

18 Eskelinen M, Ikonen J and Lipponen P: Sex-specific diagnostic scores for acute appendicitis. Scand J Gastroenterol 29: 59-66, 1994. PMID: 8128177 . DOI: $10.3109 / 00365529409090438$

19 Butt MQ, Chatha SS, Ghumman AQ and Farooq M: RIPASA score: a new diagnostic score for diagnosis of acute appendicitis J Coll Physicians Surg Pak 24: 894-897, 2014. PMID: 25523723.

20 Mikaere H, Zeng I, Lauti M, Kularatna M and MacCormick AD: Derivation and validation of the APPEND score: an acute appendicitis clinical prediction rule. ANZ J Surg 88: E303-E307, 2018. PMID: 28512853. DOI: $10.1111 /$ ans. 14022

21 Andersson $\mathrm{M}$ and Andersson RE: The appendicitis inflammatory response score: a tool for the diagnosis of acute appendicitis that outperforms the Alvarado score. World J Surg 32: 1843-1849, 2008. PMID: 18553045. DOI: 10.1007/s00268-008-9649-y

22 Anielski R, Kuśnierz-Cabala B and Szafraniec K: An evaluation of the utility of additional tests in the preoperative diagnostics of acute appendicitis. Langenbecks Arch Surg 395: 1061-1068, 2010. PMID: 19924436. DOI: 10.1007/s00423-009-0565-x

23 Aspinen S, Kinnunen M, Harju J, Juvonen P, Selander T, Holopainen A, Kokki H, Pulkki $\mathrm{K}$ and Eskelinen $\mathrm{M}$ : Inflammatory response to surgical trauma in patients with minilaparotomy cholecystectomy versus laparoscopic cholecystectomy: a randomised multicentre study. Scand J Gastroenterol 51: 739-744, 2016. PMID: 26758677. DOI: 10.3109/00365521.2015.1129436

24 Purdy M, Kokki M, Anttila M, Aspinen S, Juvonen P, Korhonen R, Selander T, Kokki H and Eskelinen M: Does the rectus sheath block analgesia reduce the inflammatory response biomarkers' IL-1ra, IL-6, IL-8, IL-10 and IL-1 $\beta$ concentrations following surgery? A randomized clinical trial of patients with cancer and benign disease. Anticancer Res 36: 3005-3011, 2016. PMID: 27272818 .

Received September 15, 2020

Revised September 30, 2020

Accepted October 2, 2020 